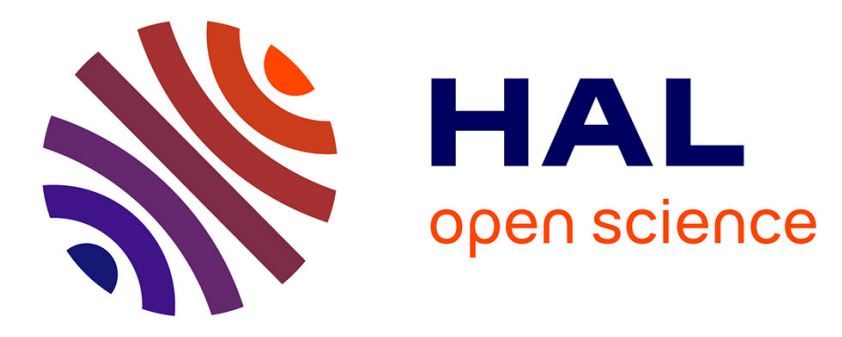

\title{
Locked-lamellar eutectic growth in thin Al-Al2Cu samples: In situ directional solidification and crystal orientation analysis
}

Sabine Bottin-Rousseau, Mehdi Medjkoune, Oriane Senninger, Laurent Carroz, Richard Soucek, Ulrike Hecht, Silvère Akamatsu

\section{To cite this version:}

Sabine Bottin-Rousseau, Mehdi Medjkoune, Oriane Senninger, Laurent Carroz, Richard Soucek, et al.. Locked-lamellar eutectic growth in thin $\mathrm{Al}-\mathrm{Al} 2 \mathrm{Cu}$ samples: In situ directional solidification and crystal orientation analysis. Journal of Crystal Growth, 2021, 570, pp.126203. 10.1016/j.jcrysgro.2021.126203 . hal-03937505

\section{HAL Id: hal-03937505 https://hal.science/hal-03937505}

Submitted on 24 Apr 2023

HAL is a multi-disciplinary open access archive for the deposit and dissemination of scientific research documents, whether they are published or not. The documents may come from teaching and research institutions in France or abroad, or from public or private research centers.
L'archive ouverte pluridisciplinaire HAL, est destinée au dépôt et à la diffusion de documents scientifiques de niveau recherche, publiés ou non, émanant des établissements d'enseignement et de recherche français ou étrangers, des laboratoires publics ou privés. 


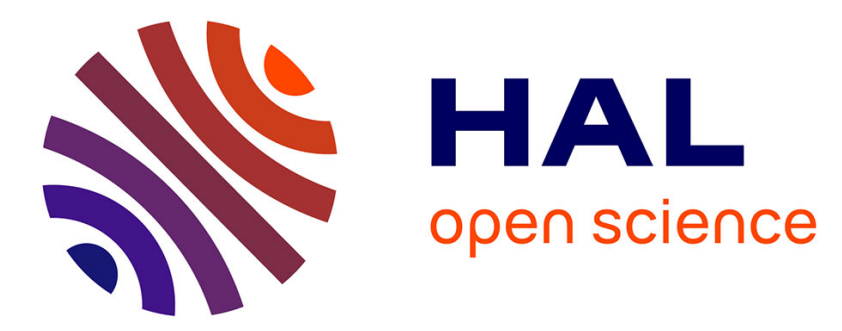

\section{Locked-lamellar eutectic growth in thin $\mathrm{Al}-\mathrm{Al} 2 \mathrm{Cu}$ samples: in situ directional solidification and crystal orientation analysis}

Sabine Bottin-Rousseau, Mehdi Medjkoune, Oriane Senninger, Laurent Carroz, Richard Soucek, Ulrike Hecht, Silvère Akamatsu

\section{To cite this version:}

Sabine Bottin-Rousseau, Mehdi Medjkoune, Oriane Senninger, Laurent Carroz, Richard Soucek, et al.. Locked-lamellar eutectic growth in thin $\mathrm{Al}-\mathrm{Al} 2 \mathrm{Cu}$ samples: in situ directional solidification and crystal orientation analysis. Journal of Crystal Growth, 2021, 570, pp.126203. 10.1016/j.jcrysgro.2021.126203 . hal-03256679

\section{HAL Id: hal-03256679 https://hal.science/hal-03256679}

Submitted on 10 Jun 2021

HAL is a multi-disciplinary open access archive for the deposit and dissemination of scientific research documents, whether they are published or not. The documents may come from teaching and research institutions in France or abroad, or from public or private research centers.
L'archive ouverte pluridisciplinaire HAL, est destinée au dépôt et à la diffusion de documents scientifiques de niveau recherche, publiés ou non, émanant des établissements d'enseignement et de recherche français ou étrangers, des laboratoires publics ou privés. 


\title{
Locked-lamellar eutectic growth in thin $\mathrm{Al}-\mathrm{Al}_{2} \mathrm{Cu}$ samples: in situ directional solidification and crystal orientation analysis
}

\author{
Sabine Bottin-Rousseau ${ }^{\mathrm{a}}$, Mehdi Medjkoune ${ }^{\mathrm{a}}$, Oriane Senninger ${ }^{\mathrm{a}, \mathrm{b}}$, Laurent Carroz $^{\mathrm{a}, 1}$, Richard Soucek ${ }^{\mathrm{a}, 2}$, Ulrike \\ Hecht $^{\mathrm{c}}$, Silvère Akamatsu ${ }^{\mathrm{a}, *}$ \\ ${ }^{a}$ Sorbonne Université, CNRS-UMR 7588, Institut des NanoSciences de Paris, case courrier 840, 4 place Jussieu, 75252 Paris Cedex 05, France \\ ${ }^{b}$ MINES ParisTech, PSL Research University, CEMEF UMR CNRS 7635, CS10207, 06904 Sophia Antipolis, France \\ ${ }^{c}$ Access e.V., Intzestr. 5, 52072 Aachen, Germany
}

\begin{abstract}
We investigated the directional-solidification dynamics of slightly hypoeutectic $\mathrm{Al}_{-} \mathrm{Al}_{2} \mathrm{Cu}$ alloys in thin samples. Our goal was to establish a link between the growth of locked, tilted-lamellar patterns and the crystal orientation relationship (OR) between the Al-rich solid solution $\alpha$ and the $\mathrm{Al}_{2} \mathrm{Cu}$ intermetallic $\theta$, as well as to gain information on the

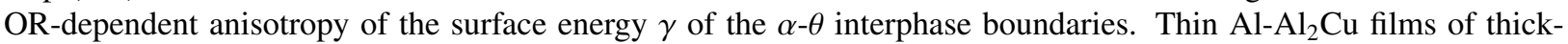
ness of $13 \pm 2 \mu \mathrm{m}$ were prepared by plasma sputtering. During solidification at pulling velocities between 0.05 and $0.5 \mu \mathrm{ms}^{-1}$, the coupled-growth front was observed in situ with a long-distance optics. The growth of millimeter-sized eutectic grains was thus followed in real time during transient and steady-state regimes. The orientation of $\alpha$ and $\theta$ crystals was measured ex situ by $\mathrm{x}$-ray diffraction and electron backscattering diffraction. In several eutectic grains, a $\{123\}^{\alpha}$ plane and a $\{100\}^{\theta}$ plane were found to be closely parallel to each other. These coincident planes define a new family of (type-C) ORs in the $\mathrm{Al}-\mathrm{Al}_{2} \mathrm{Cu}$ eutectic, which are distinct from the prevailing ORs that have been previously identified in bulk samples. Crucially, the inclination of the lamellae was systematically close to that of a $\{100\}^{\theta}$ lattice plane, which therefore corresponds to a deep $\gamma$ minimum in eutectic grains with a type- $C$ OR, or a neighbor one. We initiated a discussion on the selection of the OR, the formation of "stray" eutectic grains, and the lamellar-growth dynamics at eutectic-grain boundaries.
\end{abstract}

Keywords: A1.Directional solidification, A1.Eutectics, A1.Morphological stability, A1.Interfaces, B1.Metals

\section{Introduction}

The directional solidification of nonfaceted eutectic alloys delivers self-organized composite materials of great interest for advanced applications [1, 2, 3, 4]. Their multiphased microstructures arise from a complex nonequilibrium pattern formation process at the growth front [5, 6], some basic features of which are still poorly understood [7, 8]. This is the case for the dependence of eutectic solidification microstructures on the orientation of the crystals with respect to each other and the solidification direction [9, 10]. This crystalorientation effect has been extensively documented in

\footnotetext{
${ }^{*}$ Corresponding author

Email address: akamatsu@insp.jussieu.fr (Silvère Akamatsu)

${ }^{1}$ now at ArcelorMittal Industeel, F-71201 Le Creusot, France

${ }^{2}$ now at Institut de Chimie Organique et Analytique, CNRS UMR 7311, Université d'Orléans, 45067 Orléans, France
}

experimental studies involving the bulk solidification of binary eutectics that grow with (special) crystal orientation relationships in the solid, in particular the Al$\mathrm{Al}_{2} \mathrm{Cu}$ system [10, 11, 12, 13, 14, 15, 16, 17, 18, 19, 20]. Fundamental aspects of the problem have been addressed recently. Focus was put on the so-called floating and locked growth dynamics of lamellar eutectic patterns [21], and clear light has been cast on the role played by the anisotropy of the free energy of the interphase boundaries in the solid (interfacial anisotropy) [22, 23, 24, 25, 26, 27]. New theoretical propositions [22, 23, 24, 25] have been emitted with the support of in situ experiments implementing thin-sample directional solidification methods, and ex situ crystallographic measurements. For general-demonstration purposes, transparent and low-melting metallic eutectic alloys were used [26, 27]. However, a study using a similar methodology -in situ directional solidification in thin samples; ex situ crystallographic analysis- in a 
reference metallurgical system, and aiming at bringing further support to the recent findings on the effect of an interfacial anisotropy of the interphase boundaries during eutectic growth, was lacking.

In this paper, we present an experimental study of lamellar eutectic growth during directional solidification of $\mathrm{Al}-\mathrm{Al}_{2} \mathrm{Cu}$ alloys of near-eutectic concentration in thin samples (of thickness in the 12-15 $\mu \mathrm{m}$ range). We combined in situ solidification, and ex situ crystal-orientation analysis of the two-phased growth microstructures by using both $\mathrm{x}$-ray diffraction (XRD) and electron backscatter diffraction (EBSD). Real-time optical observations during solidification provided a unique means to grow large eutectic grains with a wellidentified microstructure, monitor the initial and transient growth stages, and follow the dynamics of steadystate lamellar growth patterns over long time and space scales. The crystal orientation relationships (ORs) between the Al-rich phase $\alpha$ and the $\mathrm{Al}_{2} \mathrm{Cu}$ phase $\theta$ was determined from EBSD data. The XRD pole-figures were used to ascertain the good crystallographic quality of the eutectic grains over large distances. By this way, we could characterize the locking dynamics of tiltedlamellar growth microstructures with full knowledge of the actual $\mathrm{OR}$ in the thin $\mathrm{Al}-\mathrm{Al}_{2} \mathrm{Cu}$ samples, and gain information on the low-energy planes for the interphase boundaries.

We found a new type of crystal orientation relationship, that is, an ensemble of ORs, which all of them characterize by a $\{123\} \alpha$ lattice plane being parallel to (in coincidence with) a $\{100\} \theta$ lattice plane, the only difference between each of these ORs being the coincident directions [17]. These ORs are unambiguously distinct from any previously reported ORs among the prevailing ones in bulk samples. We clearly establish the link between the locking dynamics of the tilted-lamellar patterns, the orientation of the growing crystals, and the interfacial anisotropy in the considered $\mathrm{Al}-\mathrm{Al}_{2} \mathrm{Cu}$ eutectic grains. We also took advantage of the in situ observations during early solidification stages to renew the discussion on the selection of ORs and the formation of eutectic grains with crystal orientation relationships that deviate substantially from the prevailing ORs in the $\mathrm{Al}-\mathrm{Al}_{2} \mathrm{Cu}$ eutectic alloy.

A brief account of the scientific bases of our work is proposed in the next section. The experimental methods are presented in section 3 , putting focus on a newly developed sample preparation method, and some instrumental developments that were imposed by the use of an alloy that solidifies at a substantially higher temperature than the low-melting alloys usually considered as model systems in thin-sample directional solidification.
In section 4, we report on a morphological characterization of tilted-lamellar microstructures, and the identification of the ORs in a reference sample first, and then in a series of eight large eutectic grains in samples with similar characteristics. The results are discussed in section 5 Conclusive remarks will be presented in the last section.

\section{Background}

We consider the directional solidification of a nonfaceted binary eutectic alloy at an imposed velocity $V$ in a fixed temperature gradient $G$. Lamellar patterns prevail in eutectic alloys that present nearly equal volume phase fraction of the two coexisting phases in the solid -this is the case for $\mathrm{Al}_{-}-\mathrm{Al}_{2} \mathrm{Cu}$. The growth dynamics is basically governed by a coupling between the propagation rate of the solid-liquid interface and the solute diffusion field in the liquid. An interphase boundary in the solid is a frozen trace of the trajectory of a triple line (trijunction) at which the liquid and the two solids are in contact with each other. At given $V$, the (inter-lamellar) spacing $\lambda$ usually falls close to a scaling length noted $\lambda_{m}$, which is proportional to $V^{-1 / 2}$ [5].

In a fully isotropic system, or, in other words, in a floating eutectic grain [21], steady periodic lamellar patterns can form, and the lamellae grow parallel to the main solidification direction. In a thin sample, the interphase boundaries align perpendicular to the sample walls, and the solidification dynamics occurs essentially in a two-dimensional geometry [28]. At given $V$, the actual value of the spacing depends on boundary and initial conditions, and can vary within a finite interval. Inside that interval (stability domain), spatial $\lambda$ modulations inherited from the initial solidification stages are smoothed out over time by a uniformization process called spacing diffusion [21, 28, 29, 30]. The stability domain is bounded, on the small- $\lambda$ side, by a lamella elimination instability, which is such that the average lamellar spacing re-increases, and reaches back a stable value. On the large- $\lambda$ side, secondary instabilities generate symmetry broken patterns, or lead to a lamellar branching that decreases the spacing (for a review, see, e.g., Ref. [8]). Interestingly, oscillatory patterns have been previously observed in $\mathrm{Al}-\mathrm{Al}_{2} \mathrm{Cu}$ samples during solidification at high rates $\left(1-10^{3} \mathrm{mms}^{-1}\right)$ by using laser-based methods [31, 32].

In a system with anisotropic interphase boundaries, the lamellar growth dynamics is substantially modified. Most commonly, the lamellae grow tilted with respect to the main solidification axis. Significant findings have been made relative to this phenomenon, which concern 
(i) the coupled-growth dynamics of tilted lamellar patterns with anisotropic interphase boundaries, and (ii) the determining crystallographic features of anisotropic eutectic grains. We shall summarize them for the sake of a self-contained presentation. A eutectic grain, within which the relative orientation of the two solid phases is fixed, can be characterized by the anisotropy function that describes the dependence of the free energy $\gamma$ of the interphase boundary on its inclination ( $\gamma$-plot). In the eutectic-growth problem, that anisotropy enters into play in the (Young-Herring) condition that expresses the local equilibrium at the trijunction, at which the interphase boundary and the two solid-liquid interfaces meet. This condition involves the anisotropic surface tension vector $\vec{\sigma}[33]$, which is defined from the $\gamma$-plot of the interphase boundary. A key feature here is that in steady-state, $\vec{\sigma}$ remains parallel, or nearly so, to the temperature-gradient axis $\mathbf{z}[22,23,24,25]$. For an arbitrary configuration, $\vec{\sigma}$ is not parallel to the interphase boundary, and the lamellae generally grow with a finite, possibly large tilt. The $\vec{\sigma} / / \mathbf{z}$ condition, also called symmetric-pattern (sp) approximation in Ref. [22], establishes that the steady-state tilt angle $\theta_{t}$ of the lamellae is determined by the $\gamma$-plot and the orientation of the eutectic grain with respect to the sample (also see supplementary material [34]). In general, a lamellar-eutectic solid contains several eutectic grains with different ORs. An OR is characterized by a pair of dense parallel planes of the crystal lattices of the two solid phases in coincidence relationship (coincident planes), and a pair of dense, coincident directions belonging to the coincident planes [35]. An interphase boundary that aligns with coincident planes realizes a local minimum of the free energy $\gamma$ of the $\alpha-\theta$ interface. During solidification, the eutectic lamellae are commonly observed to align on, or close to a coincident plane. The sp-approximation provides a good prediction of that lamellar-locking process.

A distinction between (strongly) locked, and nearly locked lamellae has been introduced, in relation with the shape of the $\gamma$-plot in the vicinity of the relevant minimum [26]. Locked lamellae are observed for a deep, possibly singular minimum of $\gamma$. Their inclination then tightly follows that minimum, irrespective of the solidification conditions. In a thin sample, the interphase boundary can also lock on a $\gamma$ minimum out of the sample plane [26]. In that case, both long- and shortrange spacing modulations are observed to persist over long solidification times, which signals that the spacing diffusion process is inactive. Nearly locked lamellar pattern are associated to a more rounded minimum of the $\gamma$-plot. The lamellar tilt angle can then deviate from that of the $\gamma$ minimum [23, 24]. More importantly, the interphase boundary can smoothly rotate about that minimum, and a spacing diffusion process remains active [36]. Therefore, in a eutectic grain with a wellidentified OR, and of known orientation with respect to the main growth axis, semi-quantitative information on both the low-energy planes, and the shape of the $\gamma$-plot in the vicinity of those planes can be gained from the observation of the dynamics of locked and nearly locked lamellar growth patterns.

A large number of ORs have been identified previously in bulk, directionally solidified $\mathrm{Al}-\mathrm{Al}_{2} \mathrm{Cu}$ ingots of near-eutectic concentration. This has been mainly attributed to the similarity of the local chemical, atomicscale order in the $\alpha$ and $\theta$ eutectic solid phases. We recall that an OR is commonly defined by the Miller indices of the coincident planes and directions. As mentioned above, distinct ORs with the same coincident planes (but different coincident directions) will be said to belong to the same type of OR. Prevailing ORs in $\mathrm{Al}-\mathrm{Al}_{2} \mathrm{Cu}$ are of two types: (i) Alpha ORs, with $\{001\}^{\alpha} / /\{001\}^{\theta}$, and (ii) Beta ORs, with $\{111\}^{\alpha} / /\{211\}^{\theta}$ [17]. Here, and in the following, we attached " $\alpha$ " and " $\theta$ " superscripts to the Miller indices of lattice planes and directions of the corresponding phase. The socalled Alpha-4 and Beta-6 ORs have been frequently reported in the scientific literature (see, e.g., [18, 20]). They are defined as follows:

$$
\begin{aligned}
& \text { Alpha-4 }\left\{\begin{array}{l}
(001)^{\alpha} / /(001)^{\theta} \\
{[130]^{\alpha} / /[100]^{\theta}}
\end{array}\right. \\
& \text { Beta-6 }\left\{\begin{array}{c}
(111)^{\alpha} / /(211)^{\theta} \\
{[\overline{1} 10]^{\alpha} / /[1 \overline{2} 0]^{\theta}}
\end{array}\right.
\end{aligned}
$$

Eutectic grains with Alpha-4 and Beta-6 ORs could be observed in one and the same ingot [19]. They presented very different microstructures. In Beta-6 eutectic grains, the lamellar microstructures are usually tilted, and exhibit a locking on the $\{111\}^{\alpha} / /\{211\}^{\theta}$ coincident planes. In contrast, Alpha- 4 grains commonly grow with the $[001]^{\alpha}$ and $[001]^{\theta}$ coincident directions nearly parallel to the temperature gradient, and exhibit a labyrinth- (or maze-)like microstructure, within which the interphase boundaries broadly align close to $\{130\}^{\alpha} / /\{100\}^{\theta}$ coincident planes during a slow evolution towards a lamellar microstructure [37]. These microstructures have been analyzed under the light of recent molecular-dynamics simulations, from which the $\gamma$-plots of the $\alpha-\theta$ interphase boundaries in solid $\mathrm{Al}-\mathrm{Al}_{2} \mathrm{Cu}$ for the Alpha-4 OR (and a near-Beta-6 OR) could be estimated for the first time [38]. This study brought a definite evidence of the fact that, in a given eutectic alloy, the $\gamma$-plot of the interphase boundaries strongly depends on the OR. 
It may be also useful to note that for a given OR, there frequently exist, in addition to the main coincident planes, one or several distinct families of low Miller index planes in near-coincidence within a few degrees. This defines a set of neighbor ORs. In particular, the Alpha-4 and Beta-6 ORs are neighbor ORs to within a relative rotation of the two crystals of about $6^{\circ}$. Finally, many authors (see, e.g., [10], [11], and [17]) insisted on the experimental fact that crystal-orientation measurements most often exhibited a substantial departure from an "ideal" OR, as well as a large spatial dispersion in a given eutectic grain.

\section{Methods}

\subsection{Thin $\mathrm{Al}-\mathrm{Al}_{2} \mathrm{Cu}$ samples}

The $\mathrm{Al}-\mathrm{Al}_{2} \mathrm{Cu}$ eutectic plateau (temperature $T_{E}=$ $548^{\circ} \mathrm{C}$; eutectic concentration $C_{E}=17.5 \mathrm{~mol} \% \mathrm{Cu}$ [39]) involves the Al-rich terminal solid solution $\alpha$ and the $\mathrm{Al}_{2} \mathrm{Cu}$ intermetallic $\theta$. There is a rather large uncertainty on the value of the alloy constant $K_{J H}=\lambda_{m}^{2} V$ (the subscript JH stands for Jackson and Hunt [5]) -in particular, it has been estimated to 135.6 and $99 \mu \mathrm{m}^{3} \mathrm{~s}^{-1}$ in Refs. [40] and [41], respectively. The lattice parameters of the face centered cubic (fcc) $\alpha$ phase, and the tetragonal (Pearson $t$ I12) $\theta$ phase at room temperature are given in Table 1 . In both phases, the lattice parameter along the (010) direction is obviously identical to the lattice parameter "a" along (100). The lattice parameter "c" is measured along (001). Our measurements (standard x-ray powder diffraction; not shown) agree well with those of Ref. [42] (but substantially depart from $\mathrm{a}=6.030 \AA$, and $\mathrm{c}=4.860 \AA$, reported in Ref. [17] for $\theta$ ). They were successfully used for indexing the two solid phases in the XRD pole figures presented in this study.

\begin{tabular}{c||c|c|c} 
Phase & $\mathrm{a}$ & $\mathrm{c}$ & \\
& {$[\AA]$} & {$[\AA]$} & \\
\hline \hline$\alpha$ & $4.049^{i} ; 4.055^{j}$ & $4.049^{i} ; 4.055^{j}$ & \\
$\theta$ & $6.067^{i} ; 6.075^{j}$ & $4.877^{i} ; 4.881^{j}$ & \\
\hline \hline
\end{tabular}

Table 1: Lattice parameters of the fcc (Al-rich) $\alpha$, and tetragonal $\theta$ $\left(\mathrm{Al}_{2} \mathrm{Cu}\right)$ eutectic phases at room temperature. i: Ref. [42]; $\mathrm{j}$ : this work.

Thin $\mathrm{Al}-\mathrm{Al}_{2} \mathrm{Cu}$ films were deposited on 1-mm thick, optically flat sapphire plates $\left[\mathrm{Al}_{2} \mathrm{O}_{3}\right.$ corundum single crystals with a $\{11 \overline{2} 0\}$ plane parallel to the surface] of lateral dimensions $60 \times 10 \mathrm{~mm}^{2}$ (Situs $\mathrm{GmbH}$ ). For this purpose, we used a magnetron sputtering device (lowpressure Ar plasma) installed in a clean room, equipped with pure $\mathrm{Al}$ and $\mathrm{Cu}$ sources (99.99 mol\%; Neyco). For obtaining a metallic film of well-defined thickness and concentration, an Al layer was deposited first on the (cleaned) sapphire plate at $200^{\circ} \mathrm{C}$, and then a $\mathrm{Cu}$ layer on top of it. A bimetallic $\mathrm{Al} / \mathrm{Cu}$ film of total thickness $\delta_{y}$ ranging between 11 and $15 \mu \mathrm{m}$ was then obtained. The ratio between the thickness of the Al layer and that of the $\mathrm{Cu}$ layer was calibrated in such a way that, after melting, the concentration $C_{0}$ of the film was nominally equal to $C_{E}$. During sputtering, a funnel-shaped mask was used to preform a crystal-selector channel (typically 200-500 $\mu \mathrm{m}$ wide), and a V-shaped crystal expander at one end of the sample. The resulting funnelshaped end of the sample can be seen in Fig. 1 Before solidification, a sapphire plate (upper plate) was pressed on top of the free surface of the as-deposited bimetallic film, and glued along the edges (ResbondTM 908) in a glovebox at room temperature under protective argon pressure. By this procedure, dewetting in the liquid state was avoided -in contrast, dewetting was dramatic on quartz substrates. During solidification, the nucleation of a few bubbles (10-100 $\mu \mathrm{m}$ in diameter) in the liquid could not be totally avoided, probably due to residual gas or dust particles. The samples could nevertheless be used for solidification over several 10 hours without further degradation. Our in situ observations indicated that the samples were actually slightly hypoeutectic $\left(C_{0}<C_{E}\right)$-we shall bring evidence to that point shortly-, which happened to be of some importance, as explained below.

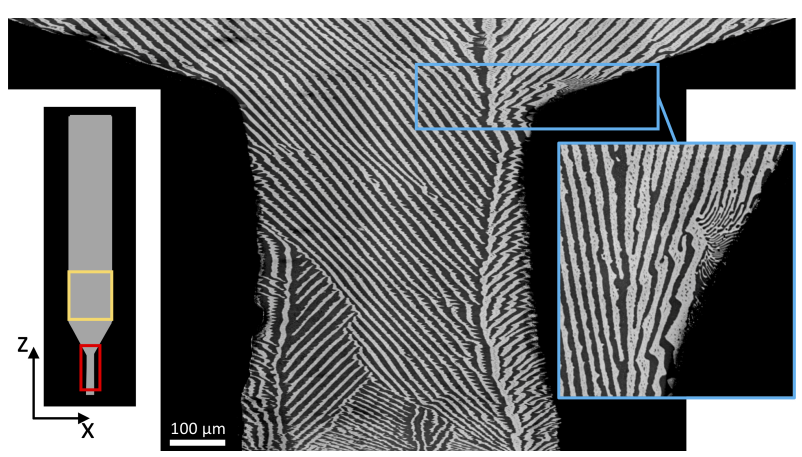

Figure 1: Solidification microstructure in the crystal-selector channel, and (a part of) the V-shaped crystal expander (ex situ panorama). Sample S1. $V=0.3 \mu \mathrm{ms}^{-1}$. The image is contracted by a factor 0.25 vertically. Inset (on the right): blue-framed detail (1:1 aspect ratio) [34]. On the left: schematic drawing of the sample film (red frame: field of view of this figure; yellow frame: see section 4.1. Color online.

A plasma sputtering method has been recently used for preparing $\mathrm{Al}-\mathrm{Al}_{2} \mathrm{Cu}$ films of sub-micrometric thick- 
ness supported on fused silica plates in a study reported in Ref. [32]. Those samples were submitted to rapid solidification with a laser beam. The resulting microstructures carefully analyzed under the light of previous fundamental studies on secondary instabilities in thin eutectics. However, no crystallographic analysis was reported by the authors.

\subsection{In situ directional solidification}

The directional-solidification instrument was designed on the model of (i) thin-sample directional solidification setups utilized in previous work (see Refs. [28] and [43]), and (ii) the apparatus that was developed by Witusiewicz and coworkers [40] for the optical observation of eutectic growth patterns in Al-based alloys in samples of thickness ranging from 200 to $700 \mu \mathrm{m}$. The temperature gradient $\left(70 \pm 10 \mathrm{Kcm}^{-1}\right.$ in the region of the solidification front) was realized along the $\mathbf{z}$ axis between two fixed, temperature regulated stainless-steel blocks separated by a $10-\mathrm{mm}$ free space. Each block was actually made of two opposing parts that contact the outer surfaces of the sample walls for good thermal control (with planar isotherms over the whole width of the samples) and translation-motion guiding. The whole device was protected from heat losses and air convection. During solidification, the translation motion of the sample holder along $\mathbf{z}$ was ensured by a linear DC motor (Physik Instrumente). Planar coupled-front patterns were observed over the full explored range of the pulling velocity $V\left(0.03-1.0 \mu \mathrm{ms}^{-1}\right)$. We will note $\mathbf{y}$ the (transverse) axis perpendicular to the sample plane, and $\mathbf{x}$ the (lateral) axis parallel to the isotherms (and perpendicular to $\mathbf{y}$ and $\mathbf{z}$ ).

Real-time observation of the metal/sapphire contact surface was performed in a reflected-light mode in the $\mathbf{y}$ direction with a long-distance optical microscope (Questar QM100). The images were captured with a monochrome camera, and sent to a computer for further analysis. In Fig. 2 2 and in following ones, in situ images are shown after global numerical filtering (noise reduction, and contrast enhancement). The liquid appears dark grey, the $\alpha$ phase light grey, and the $\theta$ phase black. The identification of the solid phases was confirmed ex situ by chemical analysis of a reference sample in a scanning electron microscope. Poor optical contrast between the liquid and the $\alpha$ phase prevented us to locate accurately the solidification front to within a few microns. In addition, the visible contour of the solid-liquid interfaces can differ substantially from its actual shape due to partial wetting of the sapphire plates by the liquid [28]. The optical device was mounted on a XYZ microstage $(\mathrm{PI})$ for scanning the microstructure in situ over the whole solidified area. After complete solidification, a reconstructed view of the microstructure of the film (panorama) was acquired from in situ images, and/or by using a systematic, ex-situ scanning procedure with a standard optical microscope. In a panorama, a line parallel to $\mathbf{x}$ obviously corresponds to an isochrone during solidification. This allowed us to measure the lamellar spacing $\lambda$ and the lamellar tilt angle $\phi$ over large spatial scales.

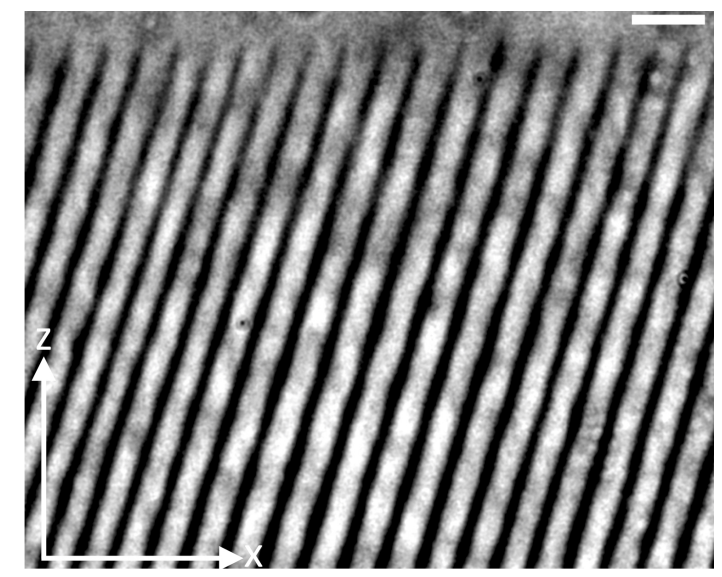

Figure 2: In situ optical image of a tilted-lamellar pattern during directional solidification of a thin $\mathrm{Al}-\mathrm{Al}_{2} \mathrm{Cu}$ sample at $V=0.3 \mu \mathrm{ms}^{-1}$ (sample S3, eutectic grain G6). $\mathbf{z}$ : solidification axis. $\mathbf{x}$ : lateral axis. The liquid (dark grey) is on top. In the solid, the $\alpha$ lamellae appear light grey, and the $\theta$ ones black. Bar $=50 \mu m$.

The experiments were carried out as follows. A sample was inserted in the directional-solidification device at room temperature. The heating blocks were then slowly set to their nominal temperatures (typically $500^{\circ} \mathrm{C}$ and $600^{\circ} \mathrm{C}$, respectively). Directional melting of the metallic film was either complete, or partial, that is, a small region at the cold end of the crystal-selector channel was left in the solid state. The sample was then left a few minutes at rest $(V=0)$ for annealing. During melting, a few isolated $\alpha$ crystals could be seen in the liquid ahead of the melting front, and, depending on the annealing time, a more or less compact polycrystalline band of the $\alpha$ phase could form in contact with the liquid [44]. This signals a slightly hypoeutectic (Al-rich side) concentration of the liquid. Directional solidification was carried out at $V=0.3-1.0 \mu \mathrm{ms}^{-1}$ in the crystal selector. We repeated that procedure (melting; growth in the crystal-selector channel) until one to three (eutectic) grains with well-identifiable microstructures were selected. An example is shown in Fig. 11 The pulling velocity was progressively slowed down during solidification along the V-shaped crystal expander. Steady- 
state solidification was then performed at fixed velocity over a long distance (typically 1 to $3 \mathrm{~cm}$ ), or by changing $V$ stepwise. The solidification front was observed in real time during the whole process, which was key to the recording of the whole solidification path, including the initial stages, during which a eutectic-grain selection occurred. We analyzed the dynamics of eight large (typically 1 to $8 \mathrm{~mm}$ of lateral extension) eutectic grains [grains G1, G2, and G3 (sample S1); grain G4 (sample $\mathrm{S} 2$ ); grains G5, G6, and G7 (sample S3); and grain G8 (sample S4)].

\subsection{Crystal orientation}

Crystal orientation measurements were performed ex situ with a Rigaku Smartlab 9kW x-ray diffractometer for XRD pole figures, and a Zeiss Gemini 1550 electron microscope equipped with an HKL Nordlys detector (Oxford INCA Crystal software) for EBSD. The upper sapphire plate was removed previous to XRD and EBSD without damaging the metallic film. During XRD measurements, we systematically recorded the $\{200\}^{\alpha}$ and $\{110\}^{\theta}$ pole figures over a large area (typically of $10 \times 10 \mathrm{~mm}^{2}$ ). Standard surface preparation techniques, including argon-ion polishing (GATAN Model 682), were used before EBSD scans. Regions of interest (ROIs) of EBSD scans (typically $900 \times 600 \mu \mathrm{m}^{2}$ ) were imaged in the electron microscope.

Measuring XRD pole-figures over large areas was useful to ascertain the presence of large eutectic grains of good crystallographic quality. This being established, we could perform EBSD measurements on smaller areas with full confidence of their being representative of a given eutectic grain on its whole. EBSD was a unique way to map the crystals in the sample, and, in the case of the presence of several eutectic grains, to determine the orientation of neighboring $\theta$ and $\alpha$ lamellae. This also allowed us to find the eutectic-grain boundaries (for example between grains G2 and G3) without any ambiguity. By comparing XRD and EBSD, we could be certain that the polishing procedure dit not alter substantially the crystalline quality of the lamellae.

In each eutectic grain, the $\alpha$ and $\theta$ crystals were indexed consistently from EBSD and XRD data. This is exemplified in Fig. 3. It shows two pole figures obtained in a single-grain sample (grain G4). In the stereographic projections, the EBSD and XRD data superimpose well on each other, to within the dispersion of the measurements. In this case, the angular dispersion $\delta_{E B S D}$ of the EBSD data was smaller than $4^{\circ}$ in both solid phases. This empirically defines a eutectic grain of good crystallographic quality. Considering the ensemble of the eutectic grains investigated in this study, the value of
$\delta_{E B S D}$ did not exceed $5^{\circ}$ in $\theta$, but could reach $\pm 10^{\circ}$ in the $\alpha$ phase. The XRD data, which were integrated over a much larger area, displayed a larger spread (in particular in $\alpha$ ). We will briefly comment these crystalmosaicity features at the end of the paper. In practice, we observed that the XRD spots with the highest intensity were systematically close to the barycenter of the EBSD data spots. We therefore used that barycenter for quantifying the orientation of the crystals in the eutectic grains under study, and identifying relevant ORs. In Fig. 3. we displayed the $(123)^{\alpha}$ and $(100)^{\theta}$ poles, calculated from EBSD measurements, thus bringing visual evidence of their being plausible coincident planes.

a)

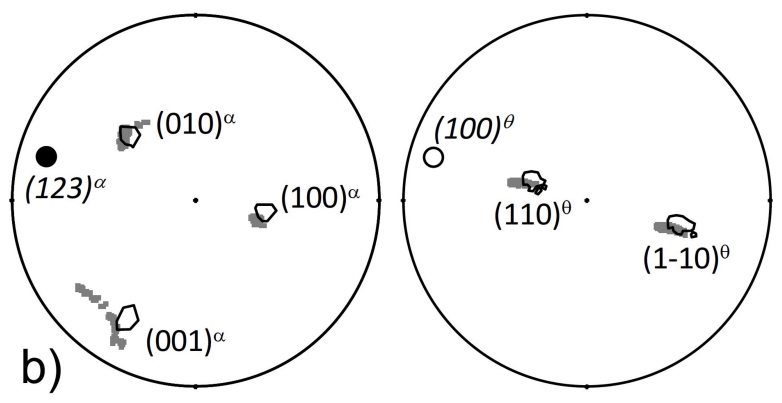

Figure 3: a) In situ image of a tilted-lamellar growth pattern $(V=$ $0.3 \mu \mathrm{ms}^{-1}$ ). Bar: $=50 \mu \mathrm{m}$. b) Stereographic projections (in the thinsample plane) of $\{100\}^{\alpha}$ (left) and $\{110\}^{\theta}$ (right) pole figures. XRD (gray symbols) and EBSD (black contours) data. Disks: calculated $(123)^{\alpha}$ (filled symbol) and $(100)^{\theta}$ (open symbol) poles. Eutectic grain G4 (sample S2).

The identification of the ORs in each grain was made by following a procedure similar to that of Ref. [27]. We calculated the mismatch angle $\Delta^{p}$ between $\alpha$ and $\theta$ lattice planes, and the angle $\Delta^{d}$ between directions belonging to those planes. We considered planes and directions with Miller indices lower than 5. Pairs of planes and directions with $\Delta^{p}$ and $\Delta^{d}$ angles larger than a threshold value that we set to $4 \mathrm{deg}$ (that is, the typical dispersion range of EBSD measurements) were dismissed. Coincident planes are expected to be of high density [35]. The atomic density $\rho$ of a lattice plane can 
be defined by $\rho=n_{2 \mathrm{D}} d / \Omega$, where $n_{2 \mathrm{D}}$ is the number of atoms per unit cell in the plane, $d$ the interplane spacing, and $\Omega$ the volume of the $3 \mathrm{D}$ unit cell. For those lattice planes that involve several atomic layers with different densities, the densest layer should be chosen. The densest planes of the $\alpha$ and $\theta$ crystal lattices are the $\{111\}^{\alpha}$ and $\{110\}^{\theta}$ planes, respectively. A sorted list of dense planes is shown in Table 2, for convenience, the atomic densities are expressed in units of the atomic density of $\{111\}^{\alpha}\left(\rho_{m} \approx 14.1 \mathrm{~nm}^{-2}\right)$. With this procedure (smallmismatch and high-density criteria), several candidate, and neighbor ORs could be found for a given eutectic grain. Other factors representing the degree of resemblance of the atomic arrangements in the coincident planes (lattice misfit, chemical order) have also been considered as parameters on which the interfacial energy of an interphase boundary may finely depend at equilibrium (see, e.g., Refs. [10], [20], and references therein). Here, we guided our analysis by focussing on the observed microstructures -essentially, the growth direction of the lamellae.

\begin{tabular}{|c|c|c||c|c|c|}
\hline$\alpha$ & $\mathrm{n}_{2 \mathrm{D}}$ & $\rho^{\alpha}$ & $\theta$ & $\mathrm{n}_{2 \mathrm{D}}$ & $\rho^{\theta}$ \\
\hline$\{111\}$ & 4 & 1 & $\{110\}$ & 4 & 0.676 \\
$\{100\}$ & 2 & 0.866 & $\{112\}$ & 8 & 0.668 \\
$\{110\}$ & 2 & 0.612 & $\{332\}$ & 10 & 0.486 \\
$\{113\}$ & 4 & 0.522 & $\{100\}$ & 2 & 0.478 \\
$\{133\}$ & 4 & 0.397 & $\{001\}$ & 2 & 0.384 \\
$\{012\}$ & 2 & 0.387 & $\{210\}$ & 3 & 0.321 \\
$\{112\}$ & 2 & 0.354 & $\{302\}$ & 5 & 0.307 \\
$\{115\}$ & 4 & 0.333 & $\{130\}$ & 4 & 0.302 \\
$\{135\}$ & 4 & 0.293 & $\{101\}$ & 2 & 0.299 \\
$\{122\}$ & 2 & 0.289 & $\{212\}$ & 4 & 0.286 \\
$\{013\}$ & 2 & 0.274 & $\{111\}$ & 2 & 0.254 \\
$\{023\}$ & 2 & 0.240 & $\{201\}$ & 2 & 0.203 \\
$\{123\}$ & 2 & 0.231 & $\{211\}$ & 2 & 0.187 \\
$\{223\}$ & 2 & 0.210 & & & \\
\hline
\end{tabular}

Table 2: Lattice planes of the $\alpha$ and $\theta$ eutectic phases with low-Miller indices, sorted in decreasing order of the atomic density $\rho^{\alpha, \theta}$ (expressed in units of the atomic density of $\left.\{111\}^{\alpha}\right) . n_{2 \mathrm{D}}$ : number of atoms per unit cell in the plane.

\section{Results}

\subsection{Reference sample}

\subsubsection{Microstructure analysis}

A panorama of the solidification microstructure in sample $\mathrm{S} 1$ is shown in Fig. 4. Three eutectic grains with tilted lamellae were identified. One grain (G1) occupied about one half of the sample (on the left in Fig.
4). The two other grains (G2 and G3) exhibited hardly distinguishable microstructures. The G2-G3 boundary was located unambiguously thanks to EBSD measurements. Its trajectory was essentially a straight line that followed the tilted inclination of the lamellae. As a consequence, grain G3 was eliminated at the right edge of the sample before the experiment ended. In contrast, the diverging boundary between G1 and G2 ran, on average, essentially parallel to the main solidification axis. The boundary operated as a source of lamellae via frequent branching events, thus evenly feeding the traveling dynamics of the tilted-lamellar patterns on both sides [45]. This, and the nearly symmetrical configuration (a fortuitous output of the early crystal-selection process) made possible the growth of the two neighboring eutectic grains over the whole experiment. Two contrasting grain-competition mechanisms were exemplified in one and the same sample: elimination (G3), and long-lived coexistence (G1/G2).

From the crystallographic analysis (see below), we learned that the three eutectic grains under consideration were actually formed from two distinct $\theta$ crystals $\left(\theta_{1}\right.$ and $\left.\theta_{2}\right)$ and two distinct $\alpha$ crystals $\left(\alpha_{1}\right.$ and $\left.\alpha_{2}\right)$. More precisely, grains G1, G2 and G3 were $\theta_{1} \alpha_{1}, \theta_{2} \alpha_{1}$, and $\theta_{2} \alpha_{2}$ eutectic grains, respectively. A morphological characterization of the microstructures in grains G1 and $\mathrm{G} 2$ will be presented shortly, and a crystallographic analysis of those grains in section 4.1.2. This will serve as a reference for the rest of the study.

The sample was solidified at five $V$ values $\left(0.07,0.05,0.1,0.2\right.$, and $0.5 \mu \mathrm{ms}^{-1}$, respectively, in chronological order). Details of the microstructures of grains G1 and G2 are shown in Fig. 5. In the micrographs, the ratio $\lambda / \lambda_{m}$ was ranging between 0.9 and 1.65 , which is ordinary for directionally solidified eutectics in thin samples. The lamellae remained tilted over the explored $V$ (and $\lambda$ ) range, but the average lamellar tilt angle $\phi_{a v}$ was not constant $\left(\left|\phi_{a v}\right| \approx 18^{\circ}\right.$ at $V=0.07 \mu \mathrm{ms}^{-1}$, and $\approx 11^{\circ}$ at $V=0.2 \mu \mathrm{ms}^{-1}$ in grain G1). At $V=0.5 \mu \mathrm{ms}^{-1}$ (Fig. 5f), the dynamics was clearly unsteady, with frequent branching events, and wavy interphase boundaries. This qualitative change signals a "2D-to-3D" transition, from an essentially two-dimensional (2D) dynamics at low velocity, thus for $\lambda$ values (say, in the order of $50 \mu \mathrm{m}$ ) larger than the sample thickness $\delta_{y}$, to a confined threedimensional (3D) dynamics at higher $V$ (and $\lambda<\delta_{y}$ ), during which the interphase boundaries deform in the transverse direction. However, short $\alpha-\theta$ facets with the same inclination as that of the interphase boundaries at low $V$ (and large $\lambda$ ) were identified in Fig. 5r. The apparent, grain-dependent departure from the nominal 


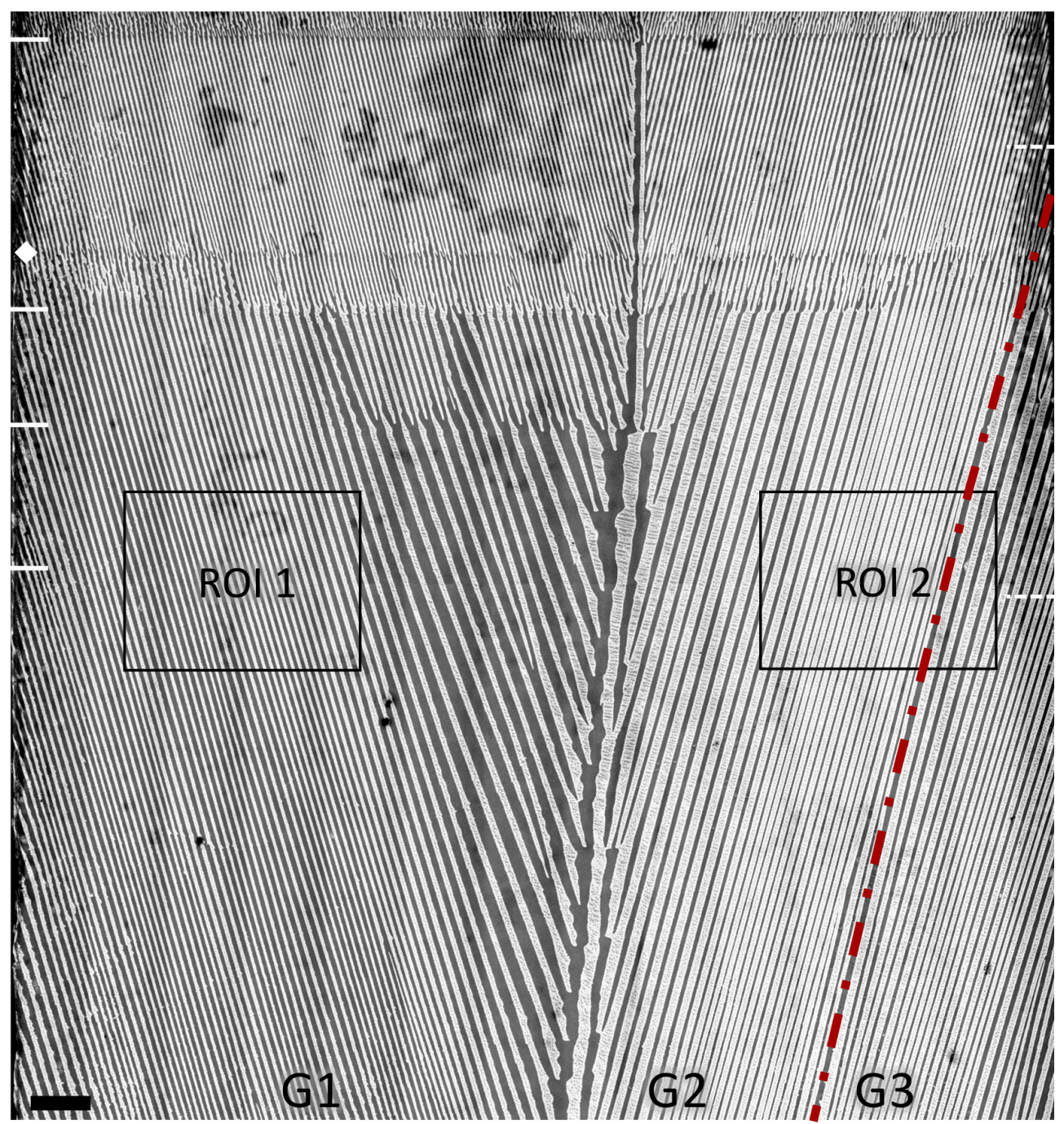

Figure 4: Ex situ panorama of sample S1, after directional solidification at five values of the pulling velocity $V$, in chronological order: $0.07,0.05,0.1,0.2$, and $0.5 \mu \mathrm{ms}^{-1}$ (white ticks on the left: velocity changes). Diamond: accidental perturbation. Dashed-dotted line: boundary between eutectic grains G2 and G3. Dashed ticks on the right: $z$ position of $\lambda(x)$ and $\phi(x)$ plots (see text). Rectangles: regions of interest (ROIs) of EBSD maps. Bar $=300 \mu m$. Also see supplementary material [34]. 
volume fraction of the two solid phases at low velocity will be briefly discussed in section 5

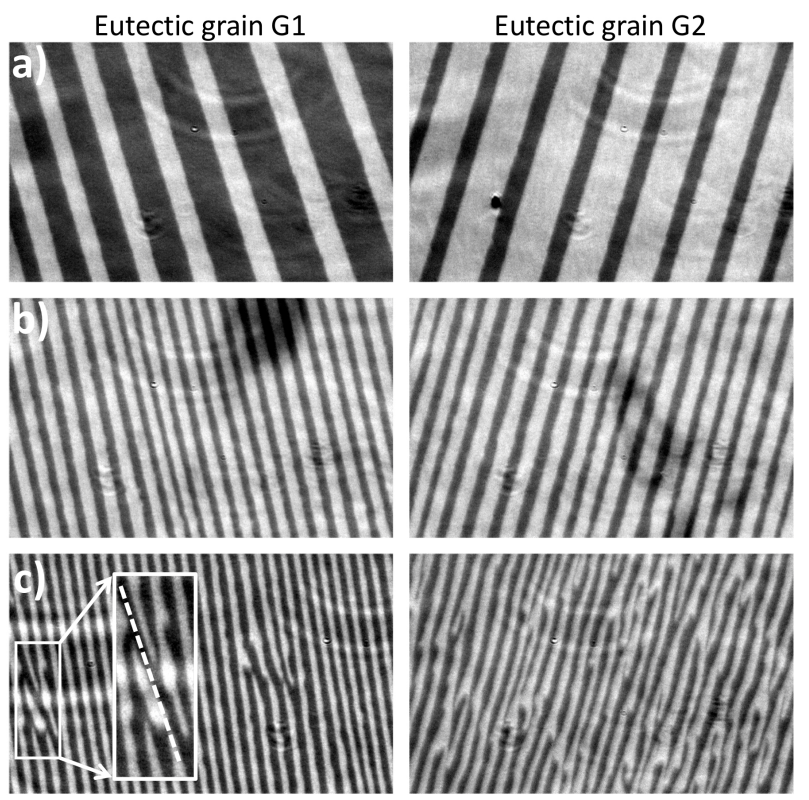

Figure 5: Details of the microstructures in eutectic grains $\mathrm{G} 1$ and G2. a) $V=0.07$; b) 0.2 ; c) $0.5 \mu \mathrm{ms}^{-1}$. In situ images (at a distance of about $100 \mu \mathrm{m}$ at the rear of the solidification front). Horizontal dimension: $500 \mu \mathrm{m}$. Inset in c): large-magnification view of the framed detail; dotted line: direction of the lamellae at low velocity in grain $\mathrm{G} 1$ as in a).

The spatial distributions of the lamellar spacing $\lambda(x)$ and the (absolute value of the) tilt angle $\phi(x)$ along the lateral axis $\mathbf{x}$ are shown in Fig. 6. They were measured at two $z$ positions in the panorama of Fig. 4-the first one at the end of the $V=0.07 \mu \mathrm{ms}^{-1}$ run, and the second one in the course of the $V=0.2 \mu \mathrm{ms}^{-1}$ run. At low velocity, grains G1 and G2 were basically composed each of two domains: (i) a small-spacing domain $\left(0.8 \lambda_{m}<\lambda<1.3 \lambda_{m}\right)$ that formed in the crystal expander at a slightly higher velocity (Fig. 11), and (ii) a largespacing domain $\left(1.3 \lambda_{m}<\lambda<2.3 \lambda_{m}\right.$; also see Fig. 5a) that was generated by lamellar branching at the G1-G2 eutectic-grain boundary. In grain $\mathrm{G} 1$, the lamellar spacing varied smoothly along $\mathbf{x}$ between the two domains (a deep minimum in the core of the large- $\lambda$ domain was due to an isolated lamellar-branching event). The lamellar tilt angle $\phi$ slightly varied between about 16 and $20^{\circ}$, and was essentially coupled to the spatio-temporal dynamics of the spacing. We shall note incidentally that a slight increase of the lamellar tilt as a function of the spacing for $\lambda$ well above $\lambda_{m}$ was also found in the numerical study of Ref. [23]. In contrast, in grain G2, $\phi$ was more or less insensitive to the spacing modulations. In both grains, no noticeable change was observed after the downward $V$ change from 0.07 to $0.05 \mu \mathrm{ms}^{-1}$, which brings additional evidence of the multistability of lamellar eutectic patterns, whereas the average lamellar spacing $\lambda_{a v}$ dramatically decreased after the $V$ changes to 0.1 , and $0.2 \mu \mathrm{ms}^{-1}$ (Fig. 6a). The spatial modulations of the patterns were then smoothed out on a large scale, but not on the scale of a few $\lambda$.
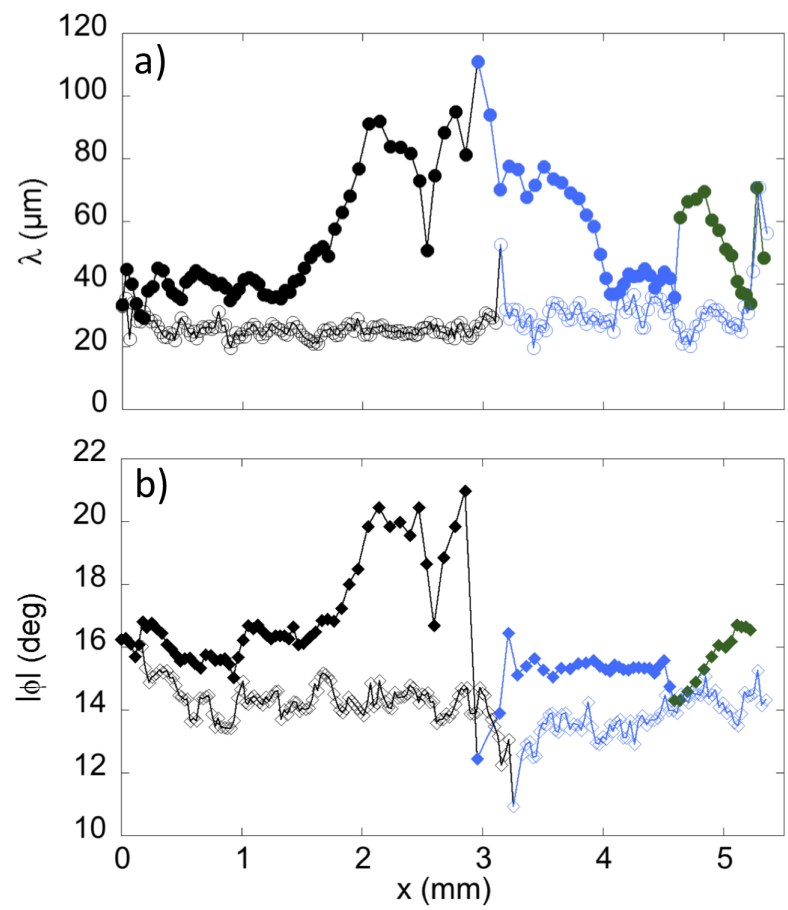

Figure 6: Spatial profile of a) the lamellar spacing $\lambda$, and b) the absolute value of the tilt angle $|\phi|$ along the $\mathbf{x}$ axis in sample $\mathrm{S} 1$. Filled symbols: $V=0.07 \mu \mathrm{ms}^{-1}$. Open symbols $V=0.2 \mu \mathrm{ms}^{-1}$. Black, blue and green symbols (color online): eutectic grains G1, G2, and G3, respectively. Also see Fig. 4

In Fig. $7 \mathrm{a}$ and $7 \mathrm{p}$, we reported the average lamellar spacing $\lambda_{a v}$ as a function of $V$ in grains G1 and G2, respectively. As mentioned above, $\lambda_{a v}$ decreased as $V$ increased, but remained larger than $\lambda_{m}$. At given $V$, the stability of the lamellar pattern was limited by a lamellaelimination instability at small spacings, and lamellar branching on the large-spacing side. The smallest value of the spacing $\lambda^{-}$, also reported in Fig. 7, was slightly below $\lambda_{m}$, which may be a signature of the "overstability" effect of lamellar eutectics at low velocity [30]. The largest value of the spacing $\lambda^{+}$was measured close to the lamellar-branching source at the G1-G2 boundary. It gives a rough estimate on the upper stability 
limit of the tilted-lamellar patterns. However, while $\lambda^{+}$ decreased smoothly as $V$ increased in grain G1, it remained essentially constant in grain G2 (for $V$ values up to $\left.0.2 \mu \mathrm{ms}^{-1}\right)$. At larger velocities $\left(V>0.2 \mu \mathrm{ms}^{-1}\right)$, an abrupt decrease of $\lambda^{+}$was provoked by numerous lamellar branching, above the 2D-to-3D transition. In the inset of Fig. 7. we reported the average value $\phi_{a v}$, and the smallest $\left(\phi^{-}\right)$and largest $\left(\phi^{+}\right)$values of the lamellar tilt angle as a function of $V$. In grain G1, $\phi_{a v}$ decreased as $V$ increased. The large apparent dispersion (measured by $\phi^{+}-\phi^{-}$) actually results from the coupling of $\phi$ with the modulations of $\lambda$, as mentioned above. It may also be useful to note that the inclination angle of the small facets visible at $V=0.5 \mu \mathrm{ms}^{-1}$ in grain G1 was very close to the $\phi^{+}$value at low $V$. In grain G2, in contrast, $\phi$ was essentially independent of the velocity in the low$V$ regime.

In summary, we can advance that grain $\mathrm{G} 2$ was of the locked type (large tilt angle insensitive to $\lambda$ and $V$; steep $\lambda$ gradients), while grain G1 was closer to a nearlylocked type (large tilt angle slightly sensitive to $\lambda$ and $V)$. The growth dynamics of the two grains changed qualitatively as $V$ increased and the lamellar spacing decreased down to below the thickness of the sample.

\subsubsection{Identification of crystal orientation relationships}

The $\{100\}^{\alpha}$ and $\{100\}^{\theta}$ pole figures shown in Fig. 8 were obtained by EBSD -ROI1 in G1, and ROI2 in G2 (and G3); see Fig. 4. It appears clearly that grains G1 and $\mathrm{G} 2$ were both issued from one and the same $\alpha_{1}$ crystal. The $\theta_{1}$ and $\theta_{2}$ crystals most probably nucleated on two different planes (of the same family) of the $\alpha_{1}$ crystal, as we will see shortly. They do not exhibit any (homophase) orientation relationship with each other. The $\theta$ crystals were oriented with the $(100)^{\theta}$ plane nearly parallel to the sample $(\mathbf{x z})$ plane, and the $(010)^{\theta}$ plane roughly perpendicular to it to within an angle $\delta_{\text {perp }}$ of $\approx 15^{\circ}$ in $\mathrm{G} 1$, and $\approx 7^{\circ}$ in grain $\mathrm{G} 2$. The $[001]^{\theta}$ direction was nearly parallel to the sample plane. We did not find any orientation relationship between either $\alpha$ or $\theta$ and the sapphire-plate crystal -in particular, there was no near-coincidence between any $\{111\}^{\alpha}$ plane $\left(<112>^{\alpha}\right.$ direction) with the (0001) plane ([110] direction) of $\mathrm{Al}_{2} \mathrm{O}_{3}$ (see, e.g., [46]). Large-scale XRD measurements integrated over an area corresponding roughly to Fig. 4 were in good agreement with the EBSD results (also see section 3.3.

We followed the procedure explained in section 3.3 for determining the ORs. In grains G1 and G2, we found coincident planes of the same families, namely, $\{123\}^{\alpha}$ and $\{100\}^{\theta}$. The $\{123\}^{\alpha} / /\{100\}^{\theta}$ coincidence defines the prevailing type of OR in the present study. We will note
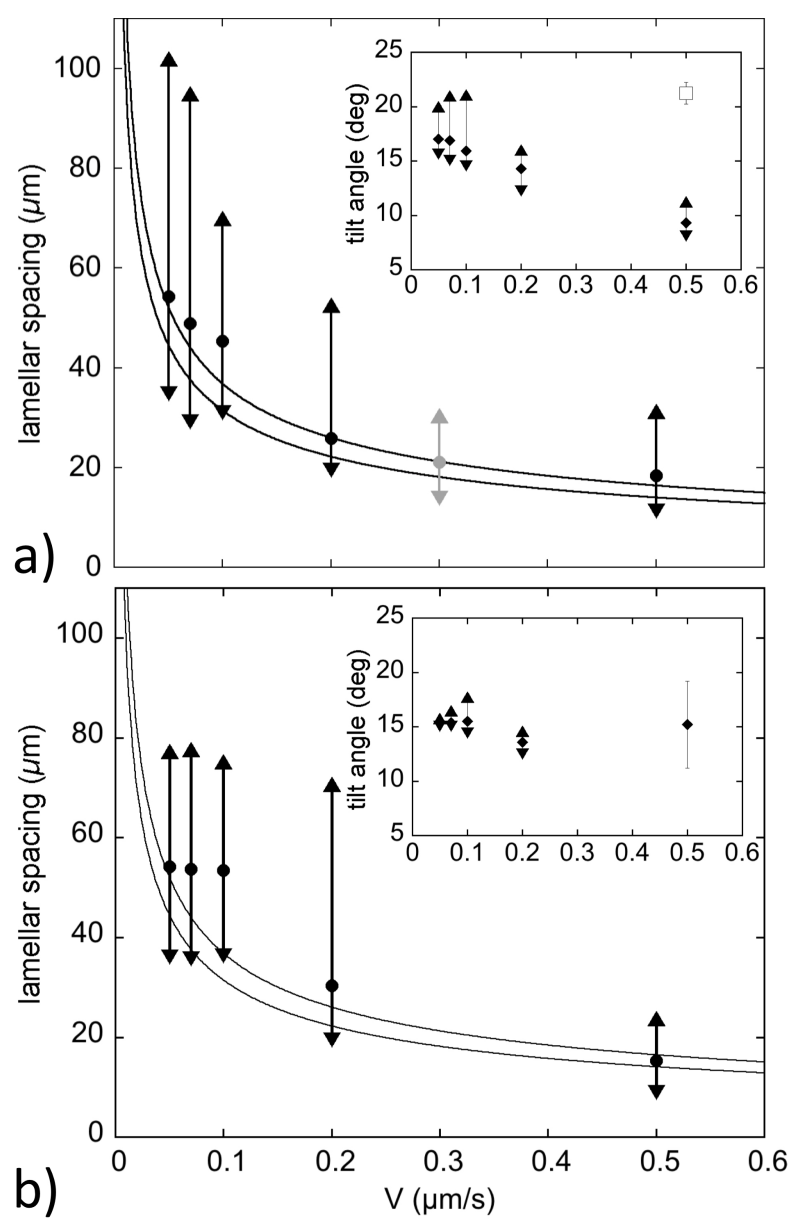

Figure 7: Lamellar spacing and tilt angle (insets) as a function of $V:$ a) eutectic grain G1 (grey symbols: eutectic grain G4); b) eutectic grain G2. Disks: $\lambda_{a v}$. Upward (downward) triangles: $\lambda^{+}\left(\lambda^{-}\right)$. Continuous lines: $\lambda_{m}$ calculated from the data of Refs. [40] and [41]. Insets: $\phi_{a v}$ (disks); $\phi^{+}$and $\phi^{-}$(upward and downward triangles, respectively); the inclination angle of the small facets at $V=0.5 \mu \mathrm{ms}^{-1}$ in grain G1 (see Fig. 5p) is also reported (open square). See text for definitions. 

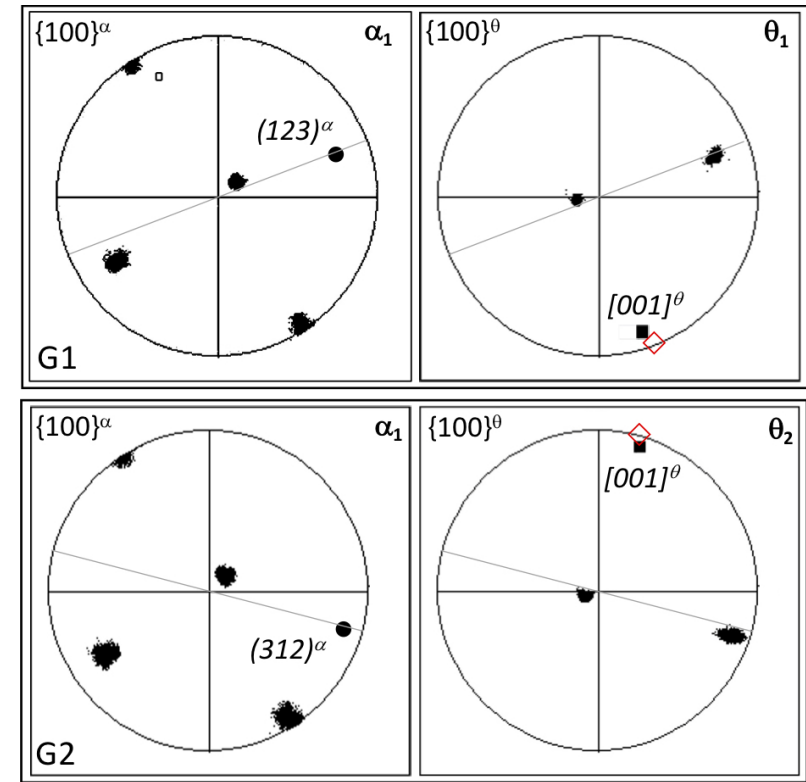

Figure 8: Stereographic projections: $\{100\}^{\alpha}$ (left) and $\{100\}^{\theta}$ (right) poles in eutectic grains G1 (top), and G2 (bottom), obtained by EBSD (regions of interest ROI1 and ROI2 in Fig. 4 respectively). Squares: $\{001\}^{\theta}$ directions. Diamonds: lamellar tilt angle. Disks: $\{123\}^{\alpha}$ poles that coincide with a $\{100\}^{\theta}$ one. Grey line: ensemble of the (poles of the) planes containing the trace of the lamellae. $\alpha_{1}, \theta_{1}, \theta_{2}$ : see text.

it "type- $C$ ". Type- $C$ ORs with different coincident directions will be noted $C_{1}, C_{2}$, etc. The $C_{1} \mathrm{OR}$, found in grain $\mathrm{G} 1$, was defined by:

$$
C_{1}\left\{\begin{array}{c}
(123)^{\alpha_{1}} / /(100)^{\theta_{1}} \\
{[30 \overline{1}]^{\alpha_{1}} / /[001]^{\theta_{1}} .}
\end{array}\right.
$$

In grain $\mathrm{G} 2$, we also found a type- $C \mathrm{OR}$, noted $C_{2}$, with another plane of the $\{123\}^{\alpha}$ family of the $\alpha_{1}$ crystal, which reads:

$$
C_{2}\left\{\begin{array}{c}
(312)^{\alpha_{1}} / /(100)^{\theta_{2}} \\
{[\overline{4} 25]^{\alpha_{1}} / /[001]^{\theta_{2}}}
\end{array}\right.
$$

In the definitions (3) and (4), we assigned the relevant $\alpha_{1}, \theta_{1}$, and $\theta_{2}$ superscripts to the Miller indices in reference to the $\alpha_{1} \theta_{1}$, and $\alpha_{1} \theta_{2}$ microstructures of grains G1 and G2, respectively. The Alpha- 4 and Beta-6 ORs were not found as good candidate ORs for those grains -as an indication, the smallest angles between $\{100\}^{\alpha}$ and $\{001\}^{\theta}$ planes, and between $<130>^{\alpha}$ and $<100>^{\theta}$ directions were both of about $15^{\circ}$. A few other pairs of planes and directions with low mismatch angles were also found. As announced in Section 3.3, we selected high-density planes and directions. In brief, the type- $C$ OR is distinct from the prevailing ORs reported in previous studies of bulk solidified $\mathrm{Al}-\mathrm{Al}_{2} \mathrm{Cu}$ ingots, and, to the best of our knowledge, none of the latter involved $\{123\}^{\alpha}$ or $\{100\}^{\theta}$ planes as coincident planes.

In Fig. 8, we also reported the average tilt angle of the lamellae on the outer circle of the stereographic projections -to be fully clear, we reported the value of $\phi$ at low $V$ and large $\lambda$ (see Fig. 7). That the lamellae (nearly) follow the $[001]^{\theta}$ direction is thus clearly evidenced. This direction obviously belongs to the $(100)^{\theta}$ coincident plane, which probably corresponds to a minimum in the $\gamma$-plot.

In summary, the two grains, G1 and G2, were issued from a single $\alpha$ crystal (noted $\alpha_{1}$ above). The $\theta_{1}$ and $\theta_{2}$ crystals nucleated independently from each other with each a $\{100\}^{\theta}$ plane in coincidence with two different $\{123\}^{\alpha}$ planes of the initial $\alpha_{1}$ crystal. In the two eutectic grains, the lamellae grew essentially parallel to the (coincident) $[001]^{\theta}$ direction. There are also strong indications that the interphase boundaries were aligning close to the $\{100\}^{\theta}$ and $\{123\}^{\alpha}$ coincident planes, which, however, were not strictly perpendicular to the sample walls. More specifically, the angular departure of the coincident planes from the normal to the sample walls was more pronounced in grain G1 than in grain G2 (Fig. 8). This could account for the difference in the lamellar growth dynamics in the two grains -locked in grain G2, and nearly locked in grain G1.

\subsection{Synoptic results}

We present here the results obtained in eutectic grains G1 to G8. A few practical details have to be mentioned first. While sample S1 (grains G1, G2, and G3) was solidified directionally at various pulling velocities (section 4.1), samples S2 to S4 (grains G4 to G8) were solidified at a unique value $\left(0.3 \mu \mathrm{ms}^{-1}\right)$ of the pulling velocity (thus in the large- $V$ regime). There was one large eutectic grain (G4) in sample S2 (see section 3.3), as well as in sample S4 (grain G8), and three grains in sample S3. Tilted lamellae have been systematically observed, except in grain G5 (see below). The results are summarized in Fig. 9 In the figure, SEM micrographs correspond to the EBSD regions of interest, and pole figures were calculated from the EBSD data -except for grain G8. The mismatch angles $\Delta^{p}$ and $\Delta^{d}$ are also reported along with the smallest angle $\Delta^{C}$ between a $\{123\}^{\alpha}$ plane and a $\{100\}^{\theta}$ plane (departure from a type- $C$ OR).

Type- $C$ ORs were identified in grains $\mathrm{G} 1, \mathrm{G} 2, \mathrm{G} 4$, and G8. The $C_{1}$ OR was found in two distinct samples (grains G1 and G4) -the growth dynamics was indeed very similar in the two eutectic grains (Figs. 3 and 5 ;), and the $\lambda_{a v}, \lambda^{-}$and $\lambda^{+}$data measured at $V=0.3 \mu \mathrm{ms}^{-1}$ in grain G4 fall in the continuity of those of grain G1 (Fig. 7a). We found neighbor type- $C$ ORs in grains 


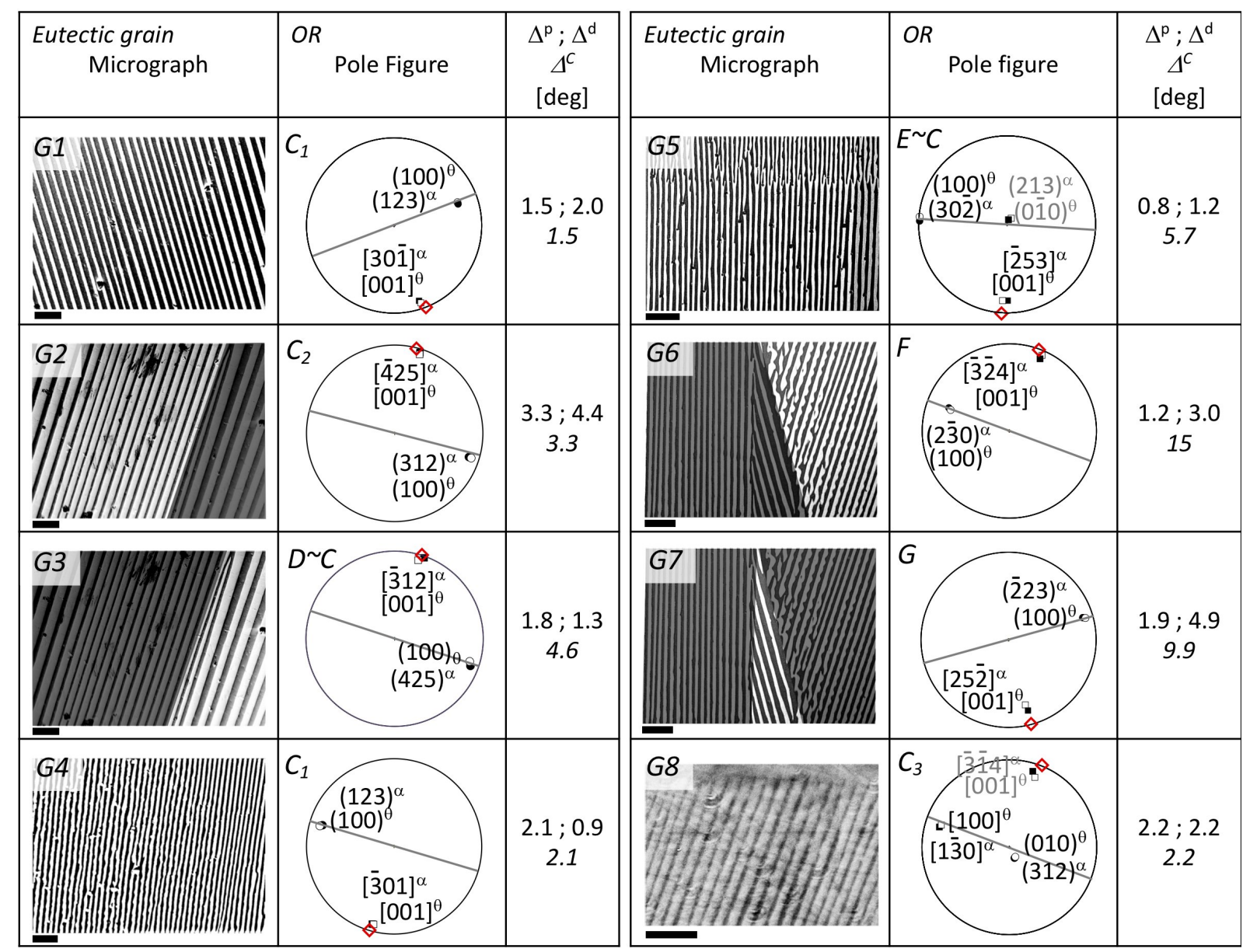

Figure 9: Regions of interest (bars: $100 \mu \mathrm{m}$ ), and EBSD measurements in eutectic grains G1 to G7 (eutectic grain G8: in situ image, and XRD measurements). Stereographic projections: coincident planes (disks) and directions (squares). Open symbols: $\theta$ phase. Filled symbols: $\alpha$ phase. Red diamonds: lamellar tilt angle. Grey line: ensemble of the planes containing the trace of the lamellae. Grey characters: alternate or neighbor coincident planes or directions. $\Delta^{p}, \Delta^{d}$, and $\Delta^{C}$ : mismatch angles between coincident planes, coincident directions, and the closest $\{100\}^{\theta}$ and $\{123\}^{\alpha}$ planes (departure form a type- $C$ OR). 
G3 and G5 (hence the notations $D \sim C$ and $E \sim C$ in Fig. 9), and two other types of ORs (noted $F$ and $G$ ) in grains G6 and G7. All ORs involved a $\{100\}^{\theta}$ coincident plane, and a $[001]^{\theta}$ coincident direction. Neither Alpha nor Beta ORs were found as low-mismatch or neighbor ORs in the eutectic grains. The direction of the lamellae was closely parallel to the $[001]^{\theta}$ direction. A coincident $\{100\}^{\theta}$ plane was nearly perpendicular to the sample walls in the eutectic grains with a (neighbor) type- $C$ OR. The lamellar microstructures were essentially similar in all the grains in the large- $V$ regime.

Let us add the following comments:

1-At first sight, in grain G5, the growth front dynamics was that of a floating, isotropic eutectic grain, with the lamellae essentially aligning with the main solidification axis $\mathbf{z}$ (Fig. 10). In fact, the $\theta$ phase was oriented with the $[001]^{\theta}$ direction aligned with $\mathbf{z}$ as well (Fig. 97 -this was probably fortuitous. The coincident $(100)^{\theta}$ and $(30 \overline{2})^{\alpha}$ planes were closely perpendicular to the sample walls. That OR was actually a neighbor type- $C$ OR (to within $\Delta^{C}=5.7^{\circ}$ ). The nearly coincident planes $(0 \overline{1} 0)^{\theta}$ and $(213)^{\alpha}$ were essentially parallel to the sample plane (grey characters in the corresponding pole figure; Fig. 9), and thus practically inaccessible to lamellar growth in a thin sample. The nearly floating aspect of lamellar growth in that grain may thus signal that the accessible $\gamma$ minimum associated to the coincident planes $(100)^{\theta} / /(30 \overline{2})^{\alpha}$ was smoother and shallower than that associated to the $\{100\}^{\theta} / /\{123\}^{\alpha}$ coincident planes in a eutectic grain with a proper type- $C$ OR. 2- In grain G8, we found a type- $C$ OR with the $(010)^{\theta}$ and $(312)^{\alpha}$ coincident planes nearly parallel to the sample plane (as in grain G5). Incidentally, the coincident directions, namely $[130]^{\alpha} / /[100]^{\theta}$, were the same as in an Alpha-4 OR -but the angle between the $(100)^{\alpha}$ and $(001)^{\theta}$ poles was of about $34^{\circ}$. It is of more practical relevance to consider the neighbor OR defined by $(130)^{\alpha} / /(100)^{\theta}$ and $[\overline{3} \overline{1} 4]^{\alpha} / /[001]^{\theta}$ (grey characters in Fig. 9, and notice that, again, the lamellae were essentially parallel to the $[001]^{\theta}$ direction, and possibly aligned with $(100)^{\theta}$. From the in situ observations (at "large" $V$ ), it was not possible to state about the locked or nearly locked character of the dynamics, and thus the relative depth of the $\gamma$ minimum as compared to the other eutectic grains.

3- The growth pattern in grain G3 (neighbor type- $C \mathrm{OR}$ ) presented a nearly locked dynamics. We will come back to this point in the next section.

4- In grains G6 (Fig. 2) and G7, the ORs were clearly distinct from a type- $C$ one, and involved an $\alpha$ plane of relatively low density in coincidence with a $\{100\}^{\theta}$ plane. However, their growth dynamics was not very different from that of type- $C$ grains.

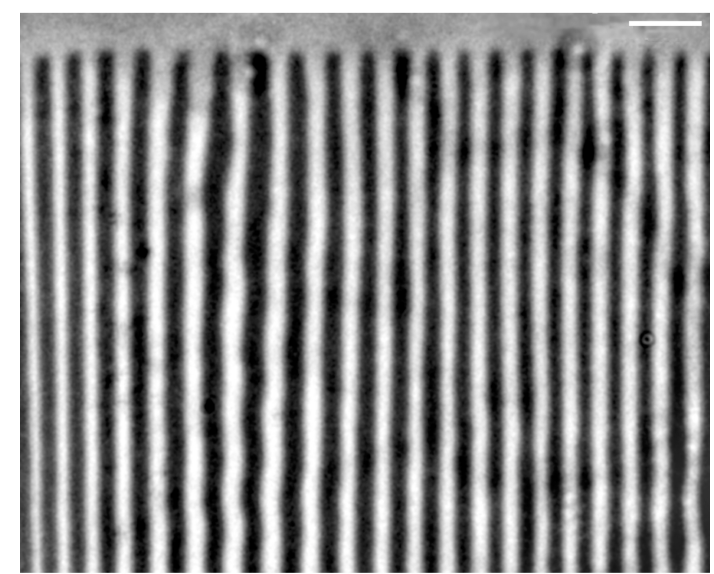

Figure 10: Lamellar front pattern during directional solidification of sample $\mathrm{S} 3$, eutectic grain $\mathrm{G} 5\left(V=0.3 \mu \mathrm{ms}^{-1}\right)$. Bar: $50 \mu \mathrm{m}$.

\section{Discussion}

Some questions that were raised in the previous sections call for further discussion. The main ones concern (i) the emergence of type- $C$ ORs, or more generally, ORs involving a $\{100\}^{\theta}$ coincident plane, and a $<001>^{\theta}$ coincident direction during initial stages, and (ii) the locked $v s$. nearly locked character of the growth dynamics in thin samples.

\subsection{Initial stages}

In the present study, eutectic grains with type- $C$ ORs were observed independently of the metallic film being completely or partially molten at the beginning of the experiments (section 3.2). This brings clear evidence that they did not form during a solid-state transformation. More plausibly, the $\theta$ crystals nucleated in the liquid, in epitaxy with pre-existing $\alpha$ crystals. Since the orientation of the crystals with respect to the sample walls was not fully arbitrary (a similar alignment effect has been observed in thin glass-wall samples of the In- $\mathrm{In}_{2} \mathrm{Bi}$ alloy [27]), it may also be advanced that the nucleation occurred preferentially close to an $\alpha$-liquidsapphire contact line. Wetting effects, coupling with liquid flow, or recrystallization during the nucleation and growth could enter into play. This process occurred on time and spatial scales that were obviously out of reach with regular optical observation means.

Further information could be gained by complementing the analysis of grains G2 and G3 in sample S1 (Figs. 
4 and 97. There is strong evidence that grain G3 was formed accidentally from grain G2, and can be qualified as a stray eutectic grain. As mentioned above, the two grains were made of the same $\theta_{2}$ crystal, whereas $\alpha_{1}$ and $\alpha_{2}$ presented a misorientation of about $13.5^{\circ}$, with a rotation axis close to the $[010]^{\alpha}$ direction. We also know from EBSD measurements (not shown) that no $\alpha_{2}$ crystals were present in the crystal selector channel, but appeared during solidification in the V-shaped crystal expander. Indeed, the inset in Fig. 1 reveals a small-scale microstructure left by an accidental multibranching event. Thanks to real-time imaging (a time sequence of images is available as a supplementary material [34]), we could observe that a relatively deep liquid pool entrapped by with an imperfection of the metallic film underwent a two-phased invasion with multiple lamellar splitting. A "stray" $\alpha_{2}$ crystal appeared during this event, most probably via plastic deformation of the initial $\alpha_{1}$ lamellae during rapid solidification nucleation seems unlikely, but cannot be ruled out. The type- $C$ OR was lost in the new $\theta_{2} \alpha_{2}$ grain G3. The growth direction of the lamellae nevertheless remained close to the $[001]^{\theta}$ direction, but, as mentioned above, the growth dynamics was of the nearly locked type. The trajectory of the G2-G3 eutectic-grain boundary was imposed by the strong locking dynamics of grain G2. Clear evidence of a mechanism giving rise to a stray grain was thus brought thanks to in situ observations. In the present case, grain G3 was eventually eliminated due to obvious geometrical features. In a different configuration with the lamellae drifting away from the sample edge, the stray grain would have been growing at the expense of the other eutectic grains. It may be important to mention that, in contrast, no substantial modification of the orientation of the crystals was detected as resulting from smooth lamellar-branching -e.g., at the G1-G2 boundary.

We propose, in summary, that type- $C$ ORs prevail in thin directionally solidified hypoeutectic $\mathrm{Al}-\mathrm{Al}_{2} \mathrm{Cu}$ samples. The $\theta$ phase nucleates on pre-existing $\alpha$ crystals. Other types of (neighbor) ORs that appear in the course of solidification are essentially due to accidental plastic deformation caused by imperfections of the sample. Similar, but milder effects (solidification around a pore or a dust particle) may also be at the origin of a mosaicity of the $\alpha$ phase. More practically, our observations show that, due to the drifting dynamics of tiltedlamellar patterns, the appearance of a micron-sized disoriented crystal caused by a localized, accidental deformation can have a large impact on the eutectic-grain structure on the scale of the ingot. Similar, yet more dramatic crystal misorientation effects have been ob- served in irregular-eutectic [47] and dendritic samples [48]. Such processes are likely to take place in the vicinity of the container walls in bulk samples as well.

In most previous studies using bulk $\mathrm{Al}-\mathrm{Al}_{2} \mathrm{Cu}$ samples, poor attention was brought to early stages of growth. However, in bulk solidified $\mathrm{Al}-\mathrm{Al}_{2} \mathrm{Cu}$ ingots that presented Alpha-4 and Beta-6 ORs [49], careful (ex situ) investigation of the microstructure left during initial stages indicated that the solidification started from a solid layer of the $\theta$ phase, whatever the concentration being (slightly) hypo- or hyper-eutectic. If this result can be extended to bulk solidification of neareutectic $\mathrm{Al}-\mathrm{Al}_{2} \mathrm{Cu}$ samples in general, this would provide an explanation to the prevailing of the so-called non-reciprocal nucleation of $\alpha$ on $\theta$ (see, e.g., [50] and references therein). Further work would be needed for a more definite conclusion. The formation of a large $\theta$-phase layer in bulk $\mathrm{Al}-\mathrm{Al}_{2} \mathrm{Cu}$ samples could be attributed to a Soret effect [51]; other macrosegregation processes such as convection may also be at play. Convection is definitely absent in thin samples, and the quantitative consequences of a Soret effect depend on the value of the temperature gradient (which was relatively modest in our study), and the holding time (which was rather short as well). This could be the main practical difference between bulk and thin samples. It is therefore tempting to advance that Alpha- and Beta-type ORs are favored by $\alpha$ nucleation onto pre-exisiting $\theta$ crystals. This hypothesis should be tested in thin hypereutectic samples via a similar methodology as in the present work.

\subsection{Lamellar locking}

In this study, the lamellar-locking effect was essentially determined by the inclination of a $\{100\}^{\theta}$ plane. One must however explain the differences in the lamellar-growth dynamics between, in particular, grains G1 (nearly locked), G2 (locked), and G5 (seemingly floating). Two parameters are to be taken into consideration: the mismatch angle $\Delta^{C}$ between the $\{123\}^{\alpha}$ and $\{100\}^{\theta}$ planes in (near) coincidence (i.e., the departure from a type- $C \mathrm{OR}$ ), and the inclination angle $\delta_{\text {perp }}$ of the coincident $\{100\}^{\theta}$ plane with respect to the sample plane xz. The strength of the lamellar locking was not simply related to the mismatch angle: for example, $\Delta^{C}$ was lower in the nearly-locked grain G1 than in the locked grain G2 -while $\delta_{\text {perp }}$ was closer to $90^{\circ}$ in G2 than in G1. This being noted, and under the light of our above comments about the dynamics in the seemingly floating grain G5 (section 4.2), we shall state that, for type$C$ ORs, and neighbor ones, the $\gamma$-plot of the interphase 
boundary presents a minimum in the vicinity of a coincident plane of the $\{100\}^{\theta}$ family. The depth and sharpness of that minimum depend on the orientation of the $\alpha$-phase coincident plane and directions. The stronglocking dynamics in grain G2 signals a sharp $\gamma$ minimum aligned with a $\{123\}^{\alpha} / /\{100\}^{\theta}$ coincident plane. The degree of locking however not only depends on the depth of the minimum, but also on its position with respect to the walls of the thin sample (i.e., the orientation of the eutectic grain). As concerns the latter point, it has been indeed made clear in Ref. [27] that the interphase boundary can lock onto a deep $\gamma$ minimum situated out of the sample plane -it is no longer perpendicular to the sample walls. There are obvious limitations to this, that is, one cannot expect a strong out-of-plane locking if the $\gamma$ minimum is not deep enough, or too much misoriented (grain G5). Several features that have been briefly mentioned above might be related to this question, including the eutectic-grain dependency of the apparent phase volume fraction (Fig. 5), and the velocity dependent 2D-to-3D morphological transition.

The existence of a finite range of forbidden orientations and/or the presence of several local $\gamma$ minima close to the coincident planes also cannot be excluded. We can mention that, for a given OR (actually Alpha4 or Beta-6), several $\gamma$ minima of various depth and (smooth or cusped) shape, including on unexpected directions, have been identified numerically in Ref. [38] incidentally, in that work, a minimum of $\gamma$ was found to involve a $\{123\}^{\alpha}$ plane, and another one, a $\{100\}^{\theta}$ plane. A recent study of the evolution of the microstructure during growth of a large Alpha-4 eutectic grain in a bulk $\mathrm{Al}-\mathrm{Al}_{2} \mathrm{Cu}$ sample indeed indicated that the growth dynamics of a given eutectic grain is sensitive to the details of such a complicated $\gamma$-plot [37].

\section{Conclusion}

In this study, we investigated the formation dynamics of tilted-lamellar growth microstructures during directional solidification of thin samples of slightly hypoeutectic $\mathrm{Al}-\mathrm{Al}_{2} \mathrm{Cu}$ alloys. We could establish a clear link between the crystallographic-locking dynamics of the coupled-growth patterns, the inclination of coincidence planes that characterize the crystal orientation relationship in large eutectic grains, and the sharpness of the corresponding minimum of the interfacial free energy of the interphase boundary. We employed a new method for the preparation of thin $\mathrm{Al}-\mathrm{Al}_{2} \mathrm{Cu}$ films on flat sapphire substrates. Real-time observations of the solidification patterns allowed us to select large eutectic grains with locked, or nearly locked lamellar microstructures. By ex situ crystallographic analysis, we identified a prevailing type of crystal orientation relationship in the two-phased solid, with $\{123\}^{\alpha} / /\{100\}^{\theta}$. The more or less locked, tilted-lamellar growth dynamics was dominated by the orientation of the $\theta$ phase, with the lamellae aligning on, or close to a $\{100\}^{\theta}$ plane. Key observations were made during initial transients. In particular, we brought direct evidence that a eutectic grain with a substantial departure from the prevailing OR type was generated by an accidental deformation, but still exhibited a locked-lamellar dynamics. It can thus be hypothesized that, in contrast with the transparent-organic and metallic systems used in previous thin-sample directional solidification studies [26, 27], eutectic grains with weakly anisotropic interphase boundaries and a fully floating dynamics are unlikely in the $\mathrm{Al}-\mathrm{Al}_{2} \mathrm{Cu}$ system.

This study will serve as a new basis for further investigation. This would include a more systematic exploration of the lamellar-growth dynamics and ORs in thin $\mathrm{Al}-\mathrm{Al}_{2} \mathrm{Cu}$ alloy samples by varying the alloy concentrations within a range that extends to hypereutectic values, thus aiming at firmly evidencing the effect of the alloy concentration on the asymmetry of the nucleation sequence of the eutectic solid phases [50], and the selection of ORs. It could be also of great interest to focus more on the lamellar-branching dynamics near a diverging eutectic-grain boundary, and to study the large-scale dynamics in the presence of smooth spacing modulations [36, 45], and to compare it to recent investigations of tilted-cell arrays during directional solidification of dilute alloys [52, 53]. Numerical simulations would be needed for a more quantitative assessment of the lamellar-locking effect in a realistic alloy such as the $\mathrm{Al}-\mathrm{Al}_{2} \mathrm{Cu}$ system -and not in simplified eutectic alloys as in Refs. [23] and [24]. In order to gain more information on the $\gamma$-plot of the $\alpha-\theta$ interphase boundary, an experimental study of the $\mathrm{Al}-\mathrm{Al}_{2} \mathrm{Cu}$ growth dynamics in thin samples by using a rotating directional solidification setup will be initiated [27]. It may therefore be possible to confirm the sharpness of the $\gamma$ minimum for a $\{123\}^{\alpha} / /\{100\}^{\theta}$ coincidence, and to explore the complexity of the $\gamma$-plot of the Alpha-4 OR [38]. Thinner samples, as in Ref. [32], could be used so that the 2Dto-3D transition could be avoided at larger velocities. Among other prospects, the thin-sample solidification methodology could be also extended to three-phased growth microstructures in Al-based alloys [54, 55]. Finally, the present study may provide fundamental hints for a practical endeavor aiming at developing new meth- 
ods for the control of textures in directionally solidified eutectic materials that present several types of ORs.

\section{ACKNOWLEDGMENTS}

We thank S. Hidki, N. Casaretto, C. Blanchard, M. Vabre, and L. Becerra for technical help. We feel keenly the absence of our late colleague Gabriel Faivre, who actively participated in this study. This work was financially supported by ANPHASES M-ERA.NET project (ANR-14-MERA-004).

\section{References}

[1] J. Kwon, M.L. Bowers, M.C. Brandes, V. McCreary, I.M Robertson, P. Sudaharshan Phani, H. Bei, Y.F. Gao, G.M. Pharr, E.P. George, M.J. Millsa, Characterization of dislocation structures and deformation mechanisms in as-grown and deformed directionally solidified NiAl-Mo composites, Acta Mater. 89 (2015) 315-326.

[2] J. Llorca, V. M. Orera, Directionally solidified eutectic ceramic oxides, Progress in Materials Science 51 (2006) 711-809.

[3] J. Choi, A. A. Kulkarni, E. Hanson, D. Bacon-Brown, K. Thornton, P. V. Braun, Processing-Dependent Microstructure of $\mathrm{AgCl}-\mathrm{CsAgCl} 2$ Eutectic Photonic Crystals, Adv. Optical Mater. 6 (2018) 1701316.

[4] J. Gussone, K. Bugelnig, P. Barriobero-Vila, J. C. da Silva, U. Hecht, C. Dresbach, F. Sket, P. Cloetens, A. Stark, N. Schell, J. Haubrich, G. Requena, Ultrafine eutectic Ti-Fe-based alloys processed by additive manufacturing - A new candidate for high temperature applications, Applied Materials Today 20 (2020) 100767.

[5] K. A. Jackson, J. D. Hunt, Lamellar and rod eutectic growth, Trans. Metall. Soc. AIME 236 (1966) 1129-1142.

[6] J. A. Dantzig, M. Rappaz, Solidification, 2nd Edition, EPFL Press, Lausanne (2016)

[7] V. Fleury, J.-F. Gouyet, E.M. Leonetti, Branching in Nature, EDP Sciences, Springer (2001).

[8] S. Akamatsu, M. Plapp, Eutectic and peritectic solidification patterns, Current Opinion in Solid State and Materials Science 20 (2016) 46

[9] L. M. Hogan, R. W. Kraft, F.D. Lemkey, Eutectic grains, Adv. Mater. Res. 5 (1971) 83-126.

[10] W. Kraft, Crystallography of equilibrium phase interfaces in Al$\mathrm{CuAl}_{2}$ eutectic alloys, Transactions of the Metallurgical Society of AIME 224 (1962) 65-75.

[11] I.G. Davies, A. Hellawell, The structure of directionally frozen Al-CuAl 2 eutectic alloy, Phil. Mag. 19 (1969) 1285-1297.

[12] I. G. Davies, A. Hellawell, Phase orientations in the lamellar and non-lamellar regions of the $\mathrm{Al}-\mathrm{CuAl}_{2}$ eutectic alloy, Phil. Mag. 20 (1970) 1255-1259

[13] B. Cantor, G.A. Chadwick, The growth crystallography of directionally solidified $\mathrm{Al}-\mathrm{Al}_{3} \mathrm{Ni}$ and $\mathrm{Al}-\mathrm{Al}_{2} \mathrm{Cu}$ eutectics, J. Cryst. Growth 23 (1974) 12-20.

[14] G. Garmong, C.G. Rhodes, The structure of interphase boundaries in Al-CuAl2 curved eutectic crystals, Metall. Trans. 5 (1974) 2507-2513.

[15] G. Garmong, C.G. Rhodes, Interfacial structure of Al-CuAl2 eutectic composites, Acta Met. 22 (1974) 1373-1382.

[16] J. P. Riquet, F. Durand, Croissance de monograins eutectiques $\mathrm{Al}-\mathrm{Al}_{2} \mathrm{Cu}$, J. Cryst. Growth 29 (1975) 217-218.
[17] R. Bonnet, F. Durand, Geometric discussion of the relationships between the phases $\mathrm{Al}$ and $\mathrm{CuAl}_{2}$ for the eutectic and precipitates of $\mathrm{CuAl}_{2}$, Conference on in situ Composites, Public NMAB 308-I, Lakerville, USA (1973).

[18] U. Hecht, V.T. Witusiewicz, A. Drevermann, S. Rex, Orientation relationship in univariant $\mathrm{Al}-\mathrm{Cu}-\mathrm{Ag}$ eutectics, Trans. Indian Inst. Met. 58 (2005) 545-551.

[19] U. Hecht, V.T. Witusiewicz, A. Drevermann, Coupled growth of $\mathrm{Al}-\mathrm{Al} 2 \mathrm{Cu}$ eutectics in Al-Cu-Ag alloys, IOP Conference Series: Mat Sci Eng 27 (2012) 012029.

[20] S.J. Wang, G. Liu, J. Wang, A. Misra, Characteristic orientation relationships in nanoscale $\mathrm{Al}-\mathrm{Al} 2 \mathrm{Cu}$ Eutectic, Materials Characterization 142 (2018) 170.

[21] B. Caroli, C. Caroli, G. Faivre, J. Mergy, Lamellar eutectic growth of CBr4-C2Cl6: effect of crystal anisotropy on lamellar orientations and wavelength dispersion, J. Cryst. Growth 118 (1992) 135-150.

[22] S. Akamatsu, S. Bottin-Rousseau, M. Şerefoğlu, G. Faivre, A theory of thin lamellar eutectic growth with anisotropic interphase boundaries, Acta Mater. 60 (2012) 3199-3205

[23] S. Ghosh, A. Choudhury, M. Plapp, S. Bottin-Rousseau, G. Faivre, S. Akamatsu, Phys. Rev. E 91 (2015) 022407.

[24] Z. Tu, J. Zhou, L. Tong, Z. Guo, A phase-field study of lamellar eutectic growth with solid-solid boundary anisotropy, J. Cryst. Growth 532 (2020) 125439.

[25] Z. Tu, J. Zhou, Y. Zhang, W. Li, and W. Yu, An analytic theory for the symmetry breaking of growth-front in lamellar eutectic growth influenced by solid-solid anisotropy, J. Cryst. Growth 549 (2020) 125851.

[26] S. Akamatsu, S. Bottin-Rousseau, M. Şerefoğlu, G. Faivre, Lamellar eutectic growth with anisotropic interphase boundaries: Experimental study using the rotating directional solidification method, Acta Mater. 60 (2012) 3206-3214.

[27] S. Bottin-Rousseau, O. Senninger, G. Faivre, S. Akamatsu, Special interphase orientation relationships and locked lamellar growth in thin In- $\operatorname{In}_{2} \mathrm{Bi}$ eutectics, Acta Mater. 150 (2018) 16-24.

[28] S. Akamatsu, S. Bottin-Rousseau, G. Faivre, Determination of the Jackson-Hunt constants of the In-In 2 Bi eutectic alloy based on in situ observation of its solidification dynamics, Acta Mater. 59 (2011) 7586-7591.

[29] S. Akamatsu, M. Plapp, G. Faivre, A. Karma, Pattern Stability and Trijunction Motion in Eutectic Solidification, Phys. Rev. E 66 (2002) 30501(R)

[30] S. Akamatsu, M. Plapp, G. Faivre, A. Karma, Overstability of lamellar eutectic growth below the minimum-undercooling spacing, Metall. Mat. Trans. A 35 (2004) 1815-1828.

[31] M. Zimmermann, A. Karma, M. Carrard, Oscillatory lamellar microstructure in off-eutectic Al-Cu alloys, Phys. Rev. B 42 (1990) 833-837.

[32] E.J. Sullivan, J.A. Tomko, J.M. Skelton, J.M. Fitz-Gerald, P.E. Hopkins, J.A. Floro, Lamellar instabilities during scanning laser melting of $\mathrm{Al}-\mathrm{Cu}$ eutectic and hypoeutectic thin films, Journal of Alloys and Compounds 865 (2021) 158800.

[33] D. W. Hoffman, J. W. Cahn, Vector thermodynamics for anisotropic surfaces. 1. Fundamentals and application to plane surface junctions, Surface Science 31 (1972) 368

[34] Supplementary material is made available.

[35] A.P. Sutton, R. W. Balluffi, Interfaces in Crystalline Materials, Oxford University Press (2009).

[36] M. Ignacio, M. Plapp, Spacing homogenization in lamellar eutectic arrays with anisotropic interphase boundaries, Phys. Rev. Materials 3 (2019) 113402.

[37] U. Hecht, J. Eiken, S. Akamatsu, S. Bottin-Rousseau, Phase boundary anisotropy and its effects on the maze-to-lamellar transition in a directionally solidified $\mathrm{Al}-\mathrm{Al}_{2} \mathrm{Cu}$ eutectic, Acta 
Mater. 170 (2019) 268-277.

[38] R. Kokotin, U. Hecht, Molecular dynamics simulations of Al$\mathrm{Al}_{2} \mathrm{Cu}$ phase boundaries, Comput. Mater. Sci. 86 (2014) 30-37.

[39] Binary Alloys Phase Diagram, Volume 3, ASM International, Materials Park, Ohio (2006).

[40] V. Witusiewicz, U. Hecht, S. Rex, In-situ observation of eutectic growth in Al-based alloys by light microscopy, J. Cryst. Growth 372 (2013) 57-64

[41] O. Senninger, M. Peters, P. Voorhees, Two-phase eutectic growth in $\mathrm{Al}-\mathrm{Cu}$ and $\mathrm{Al}-\mathrm{Cu}-\mathrm{Ag}$, Metal. Mater. Trans. A 49 (2018) 1692-1707.

[42] A. Meetsma, J. L. De Boer, S. Van Smaalen, Refinement of the crystal structure of tetragonal $\mathrm{A} 12 \mathrm{Cu}$, Journal of Solid State Chemistry 83 (1989) 370-372.

[43] S. Akamatsu, S. Bottin-Rousseau, M. Perrut, G. Faivre, L. Sturz, V. T. Witusiewicz, Real-time study of thin and bulk eutectic growth in Succinonitrile-(D)Camphor alloys, J. Cryst. Growth 299 (2007) 418-428.

[44] S. Akamatsu, S. Moulinet, G. Faivre, The formation of lamellar eutectic grains in thin samples, Metall. Mater. Trans. A 32 (2001) 2039-2048.

[45] G. Faivre, J. Mergy, Tilt bifurcation and dynamical selection by tilt domains in thin-film lamellar eutectic growth: Experimental evidence of a tilt bifurcation, Phys. Rev. A 45 (1992) 7320-7329.

[46] Y. Zhu, W. Wang, W. Yang, H. Wang, J. Gao, G. Li, Nucleation mechanism for epitaxial growth of aluminum films on sapphire substrates by molecular beam epitaxy, Materials Science in Semiconductor Processing 54 (2016) 70-76.

[47] C.M. Gourlay, K. Nogita, A.K. Dahle, Y. Yamamoto, K. Uesugi, T. Nagira, M. Yoshiya, H. Yasuda, In situ investigation of unidirectional solidification in $\mathrm{Sn}-0.7 \mathrm{Cu}$ and $\mathrm{Sn}-0.7 \mathrm{Cu}-0.06 \mathrm{Ni}$, Acta Mater. 59 (2011) 4043-4054.

[48] T. Werner, M. Becker, J. Baumann, C. Pickmann, L. Sturz, F Kargl, In situ observation of the impact of hydrogen bubbles in Al-Cu melt on directional dendritic solidification, Journal of Materials Science 56 (2021) 8225-8242.

[49] U. Hecht, unpublished results.

[50] C. Lemaignan, Initial stages of eutectic solidification, Acta Met. 29 (1981) 1379-1384.

[51] B. N. Bhat, Effect of thermotransport on directionally solidified aluminium-copper eutectic, J. Cryst. Growth 28 (1974) 68-76 (1974).

[52] D. Tourret, A. Karma, Growth competition of columnar dendritic grains: A phase-field study, Acta Mater. 82 (2015) 64-83.

[53] Y. Song, S. Akamatsu, S. Bottin-Rousseau, A. Karma, Propagative selection of tilted array patterns in directional solidification, Phys. Rev. Mat. 2 (2018) 053403.

[54] P. Steinmetz, A. Dennstedt, M. Serefoğlu, I. Sargin, A. Genau, U. Hecht, Crystal orientation relationships in ternary eutectic Al-Al2Cu-Ag2Al, Acta Mater. 157 (2018) 96-105.

[55] S. Mohagheghi, U. Hecht, S. Bottin-Rousseau, S. Akamatsu, G. Faivre, M. Şerefoğlu, Effects of interphase boundary anisotropy on the three-phase growth dynamics in the $\beta(\operatorname{In})-\operatorname{In} 2 \mathrm{Bi}-\gamma(\mathrm{Sn})$ ternary-eutectic system, IOP Conf. Series: Materials Science and Engineering 529 (2019) 012010. 